\title{
LA CRECIENTE DEPENDENCIA DE MANO DE OBRA MIGRANTE PARA TAREAS AGRÍCOLAS EN EL CENTRO GLOBAL. UNA PERSPECTIVA COMPARADA
}

\author{
Yoan Molinero-Gerbeau \\ Instituto de Economía, Geografía y Demografía (IEGD-CSIC) \\ yoan.molinero@cchs.csic.es \\ ORCID iD: https://orcid.org/0000-0002-9808-1106
}

Recibido: 15/07/2019; Aceptado: 26/11/2019.

Cómo citar este artículo/Citation: Molinero-Gerbeau, Yoan (2020). La creciente dependencia de mano de obra migrante para tareas agrícolas en el centro global. Una perspectiva comparada. Estudios Geográficos, 81 (288), e031. https://doi.org/10.3989/estgeogr.202046.026

RESUMEN: Numerosos estudios, sobre todo en las últimas décadas, han señalado el progresivo aumento del número de migrantes realizando trabajo agrícola en los Estados del centro global. Desde el paradigma de la ecología-mundo, se teorizó sobre el hecho de que este fenómeno mundial constituía una estrategia sistémica para mantener estables y bajos los precios de la comida, siendo la producción de ésta, un pilar que sustenta las fases de acumulación del capitalismo. Con el objetivo de contribuir a reforzar dicha teoría, este artículo pretende, a través de un estudio de casos comparados, dimensionar este fenómeno. Así, se dará cuenta a través de las estadísticas oficiales disponibles, de la magnitud del irreversible y estructural proceso de "migrantización" del trabajo agrícola ocurrido en las áreas centrales mundiales entre mediados del siglo pasado y principios de este.

PALABRAS CLAVE: trabajadores agrícolas migrantes; ecología-mundo; agricultura; estructuralismo; temporeros; programas de migración temporal.

\section{THE GROWING DEPENDENCE ON MIGRANT LABOR FOR AGRICULTURAL TASKS IN THE GLOBAL CORE. A COMPARATIVE PERSPECTIVE}

ABSTRACT: Several studies, especially in recent decades, have shown the progressive increase in the number of migrants doing agricultural work in the States of the global core. From the ecology-world paradigm, it was theorized that this global phenomenon constituted a systemic strategy to keep food prices stable and low, as food production is a pillar that supports the accumulation phases of global capitalism. With the aim of contributing to reinforce this theory, this article intends, through a study of comparative cases, to dimension this phenomenon. Thus, through the use of available official statistics, the magnitude of the irreversible and structural "migrantization" process of agricultural work occurred in the core areas of the world between the middle of the last century and the beginning of this one, will be analyzed.

KEYWORDS: migrant farmworkers; world-ecology; agriculture; structuralism; seasonal workers; temporary migration programs.

Copyright: (C) 2020 CSIC. Este es un artículo de acceso abierto distribuido bajo los términos de la licencia de uso y distribución Creative Commons Reconocimiento 4.0 Internacional (CC BY 4.0). 


\section{INTRODUCCIÓN}

En las últimas décadas, el estudio del trabajo agrícola realizado por migrantes en los países del centro global ha ido atrayendo la atención de una creciente comunidad académica. Si bien existían ya numerosas investigaciones en algunos países con un largo recorrido histórico en la materia, como en Estados Unidos (Calavita, 1992) o Canadá (Boyd et al., 1986), otros, en cambio, como los diversos casos europeos (Corrado et al., 2017; Gertel y Sippel, 2014), del Pacífico (Curtain et al., 2018; Underhill y Rimmer, 2016) o Asia (Ando y Horiguchi, 2013), son más recientes, revelando que se trata de un fenómeno contemporáneo y en expansión a nivel mundial. Por lo general, quienes han analizado estos contextos, han explicado la progresiva sustitución de trabajadores nacionales por migrantes en función de factores productivos tales como los procesos de industrialización del sector agrícola experimentados en determinados enclaves (Molinero-Gerbeau y Avallone, 2018) que requirieron emplear grandes cantidades de trabajadores. Entre los factores sociológicos también argüidos, se han tendido a destacar los efectos que el aumento del bienestar económico ha tenido en las poblaciones rurales del centro como, por ejemplo, hacer del trabajo agrícola un empleo no atractivo debido a su mínima remuneración, su bajo prestigio social y sus extenuantes dinámicas laborales (López-Sala, 2016).

Si bien estos análisis han contribuido a arrojar luz sobre los contextos estudiados por sus autores, el fenómeno siempre ha sido analizado ya sea de manera local, nacional o supranacional (por ejemplo, con el caso de la Unión Europea) sin incidir en el carácter puramente global que también presenta. El hecho de que una gran parte de los países del centro vea aumentar de forma considerable el número de trabajadores migrantes en su sector agrícola, tiene sin duda, desde un punto de vista Estructuralista ${ }^{1}$, raíces sistémicas, conectadas con la evolución del capitalismo global.

Esta investigación hará referencia al término "migrantización", un neologismo utilizado de forma recurrente en otras investigaciones (Mata Codesal, 2016; De Genova et al. 2018), que se refiere al hecho de considerar al migrante como un elemento social distinto, o a las migraciones, como una categoría de análisis propia. En este caso, al hablar de "migrantización" de la agricultura, se persigue el objetivo de reflejar cómo, de una forma relevante, creciente y estructural, el trabajo en el sector primario en los países del centro es cada más dependiente de la mano de obra migrante, conformada en una categoría social propia debido a que dispone de unos condicionantes legales, sociales y de movilidad que afectan de forma exclusiva a este colectivo.

Tal como ya sucedió durante los períodos coloniales, con el desplazamiento de trabajadores de los territorios ocupados hacia los nuevos espacios conquistados y organizados en monocultivos de exportación, hoy día, los migrantes de esa misma periferia global vuelven a ser determinantes para la producción de comida barata (Moore, 2015; Sayad, 2010). En una investigación previa (Molinero-Gerbeau y Avallone, 2016), conectamos este fenómeno, en su vertiente contemporánea, con el paradigma de la ecología-mundo, para explicar que los migrantes constituyen, al igual que la mano de obra colonizada en el pasado, un ejército de reserva global cuyo empleo a bajo coste se ha convertido en un factor productivo estructural que ha permitido mantener no solo el sector agrícola, sino el propio sistema capitalista mundial, al ser uno de los pilares en los que se basan los procesos de acumulación (Moore, 2015).

Dicha investigación contribuyó a ampliar los conocimientos sobre ecología-mundo desarrollando el nexo entre migraciones, trabajo barato, cadenas globales y producción de comida barata, pero, al basarse principalmente en referencias a estudios de casos, no alcanzó a cuantificar la dimensión del fenómeno. El objetivo de este artículo será por tanto el de, mediante el uso de fuentes estadísticas secundarias, contribuir a contrastar, desde un punto de vista numérico, tanto la magnitud de este fenómeno en los países del centro global, como su dinámica expansiva. Basándose así en la máxima expuesta por King, Keohane y Verba (1994), este artículo perseguirá aportar más evidencias a la teoría de la ecología-mundo con el fin de comprobarla y reforzarla.

Para llevar a cabo este análisis se desarrollará un estudio comparado de casos. Como podrá verse en el próximo apartado, la selección de los mismos tendrá que ver con un criterio fundamental: las principales mediciones Estructuralistas sobre la geoposición de los Estados en la ecología-mundo coinciden en considerar a estos como parte del centro.

Para desarrollar esta investigación, en primer lugar, se llevará a cabo una breve caracterización de los casos. Tras esto, se procederá a analizar, mediante el uso de las fuentes estadísticas disponibles, la magnitud del proceso de "migrantización" de sus sectores 
agrícolas. Para ello, siempre que las particularidades del caso lo permitan, se analizarán tres dimensiones concretas. Por un lado, se estudiará el stock de migrantes trabajando de forma permanente en sus respectivos sectores agrícolas. Por el otro, se expondrán datos sobre entradas anuales de trabajadores temporales en los Programas de Migración Temporal (PMT). Por último, siempre que los datos tengan ese nivel de desagregación, se mostrará el origen nacional de la mano de obra mencionada en las dos dimensiones previas. Todo ello permitirá así determinar no solo la importancia que tienen los migrantes dentro de la composición de la mano de obra agrícola de los Estados del centro, sino que permitirán dimensionar el fenómeno y, al presentar series históricas, mostrar su tendencia creciente. En aquellos casos donde la incidencia del trabajo irregular sea relevante, se aportarán también mediciones y estimaciones de esta dimensión.

Así pues, los datos presentados a continuación permitirán señalar que el proceso de "migrantización" de los sectores agrícolas de los Estados del centro de la ecología-mundo, es una realidad. Esto deriva tanto del importante peso relativo que ocupan los migrantes en la mano de obra total, como de la existencia de una tendencia histórica creciente que permita concluir la estructuralidad del fenómeno.

Para ello, se comenzará en la primera sección aportando algunas categorías teóricas fundamentales que servirán para la comprensión del paradigma de la ecología-mundo, así como para identificar qué es considerado el centro global. Seguidamente, se expondrán algunas de las características fundamentales que afectan al tipo de migraciones analizadas, señalando su capacidad de agencia dentro de la macro-estructura descrita. Más adelante se presentará el estudio comparado de casos y, por último, en el apartado final, se mostrarán las conclusiones de este artículo.

\section{El CENTRO de LA ECOLOGÍA-MUNDO}

La idea de que el mundo está conformado por áreas centrales y periféricas dentro de un único sistema global, el sistema capitalista, conforma la esencia de las teorías Estructuralistas de Relaciones Internacionales (Brown y Ainley, 2009). El origen de esta perspectiva se remonta a los años 50 del siglo XX, cuando la Comisión Económica de las Naciones Unidas para América Latina y el Caribe (CEPAL) dirigida entonces por Raúl Prebisch, expuso la teoría de la dependencia, que se basaba, de una forma muy simplificada, en denunciar que el comercio internacional no se realizaba entre iguales. Dentro de esta relación desigual, como expuso Wallerstein (1983: 32) «puede llamarse a la zona perdedora "periferia" y a la ganadora "centro"». Así pues, las teorías Estructuralistas, y, sobre todo, la teoría del sistema-mundo de Wallerstein, partirán de la base de que el sistema capitalista global se compone, por un lado, de áreas centrales, donde hay una mayor acumulación de producción monopolística y de capital constante (Wallerstein, 2004) y, por el otro, de áreas periféricas, abundantes en capital variable con el que comercian, de forma desigual, según los términos impuestos por los Estados del centro. "Así, el capitalismo conlleva no solo la apropiación de plusvalía de un propietario hacia un trabajador, sino también una apropiación de plusvalía de toda la economía-mundo hacia áreas centrales» (Wallerstein, 2000: 86).

Por supuesto, cuando Wallerstein, y el resto de teóricos que han desarrollado su perspectiva analítica, se refieren a la dinámica "centro-periferia" del sistema-mundo, hablan de un "concepto relacional» (Wallerstein, 2004: 17) pues esta relación asimétrica de poder no solo es espacial, sino temporal. Si en el siglo XIX, la producción de textil determinaba los procesos de acumulación mundiales, en el capitalismo neoliberal, con el desarrollo de cadenas globales, cada nexo de las mismas, en función de la proporción de plusvalía que acumule, determinará su pertenencia al centro o la periferia. Queda bastante claro, por lo tanto, que la consideración de un área como central o periférica viene marcada por la relación de procesos productivos y no por su posición geográfica. Aun así, como señala Wallerstein (1983), se puede hablar de Estados del centro y Estados de la periferia pues, para poder desarrollar los cuasi monopolios que permiten una mayor acumulación de plusvalía, se requiere de fuertes estructuras estatales cuyas maquinarias jurídicas, políticas y militares estén orientadas a asegurarse de que los Estados periféricos permanezcan en esta condición e, incluso, se debiliten.

Siguiendo esta perspectiva, diversos investigadores Estructuralistas a lo largo de las últimas décadas han propuesto modelos para clasificar los Estados según su posición geoestratégica dentro del sistemamundo. Partiendo de un consenso sobre el hecho de que la tricotomía (es decir, la existencia de un centro, una periferia y una semiperiferia) es real, 
varios autores han propuesto modelos diversos que, en función de los elementos priorizados, amplían, reducen o modifican las clasificaciones aportadas por otros autores. Algunos han expuesto complejos macro modelos, con numerosas variables, otros, sin embargo, se han guiado por mediciones más simples, como los ingresos, encontrándose también autores que han incorporado variables políticas como el poder, medidas de bienestar o la capacidad para generar cambios en el sistema global (Babones, 2005). Curiosamente, ni Jason W. Moore, autor de la mayor reformulación reciente de las teorías del sistema-mundo, la ecología-mundo, ni los diversos teóricos que han desarrollado esta perspectiva, han contribuido al debate sobre cuáles son el centro y la periferia actuales. Como puede verse en algunos de los escritos más icónicos de dicha teoría (Moore, 2003; 2016), se da por hecho que la tricotomía define la división mundial, pero no se trabaja la misma, demostrando que entre el sistema-mundo y la ecología-mundo hay una coincidencia teórica en este aspecto.

La tabla 1 muestra, de forma comparada, algunas clasificaciones realizadas en las dos últimas décadas por diversos autores Estructuralistas incluyendo, además, la del World Economic Situation and Prospects (WESP) de Naciones Unidas, que no parte de una perspectiva Estructuralista, pero permite mostrar cómo clasificaciones de fuera de la teoría convergen con esta en algunos puntos.

Como puede observarse en la tabla presentada, aunque existen variaciones entre las diversas clasificaciones, estas tienden a ser mínimas. Por ejemplo, un área que genera disensos entre los autores mostrados es la Unión Europea, siendo considerada por algunos en su totalidad con una zona central (United Nations, 2018), por otros, solo la UE-15, aunque con excepciones (Babones (2005); Dunaway y Clelland (2017)) y para Chase-Dunn, et al. (2000) solo parte de los Estados que componen dicho bloque pueden ser considerados como áreas centrales. Si en América todas las clasificaciones presentadas coinciden, en Asia, las divergencias tienen que ver, por ejemplo, con la inclusión o no de Estados como Singapur o Israel.

Dado que el objetivo de este trabajo no es el de aportar una clasificación propia, para los estudios de casos presentados a continuación se utilizará la clasificación de Chase-Dunn et al. (2000) debido no solo a su fiabilidad, sino porque los Estados que incluye, están presentes también en el resto de clasificaciones, siendo su consideración como áreas centrales un hecho consensuado en la comunidad Estructuralista.

TABLA 1

LISTADO COMPARADO DE CLASIFICACIONES DEL CENTRO DEL SISTEMA-MUNDO

\begin{tabular}{|c|c|c|c|c|}
\hline & $\begin{array}{c}\text { Chase-Dunn, Kawano y } \\
\text { Brewer }(2000)^{2}\end{array}$ & Babones (2005) & Dunaway y Clelland (2017) & $\begin{array}{l}\text { United Nations } \\
(2018)^{3}\end{array}$ \\
\hline América & $\begin{array}{c}\text { Canadá } \\
\text { Estados Unidos }\end{array}$ & $\begin{array}{c}\text { Canadá } \\
\text { Estados Unidos }\end{array}$ & $\begin{array}{c}\text { Canadá } \\
\text { Estados Unidos }\end{array}$ & $\begin{array}{c}\text { Canadá } \\
\text { Estados Unidos }\end{array}$ \\
\hline Asia-Pacífico & $\begin{array}{c}\text { Australia } \\
\text { Japón } \\
\text { Nueva Zelanda }\end{array}$ & $\begin{array}{l}\text { Australia } \\
\text { Hong Kong } \\
\text { Israel } \\
\text { Japón } \\
\text { Nueva Zelanda } \\
\text { Singapur }\end{array}$ & $\begin{array}{c}\text { Australia } \\
\text { SARS chinos } \\
\text { Japón } \\
\text { Nueva Zelanda } \\
\text { Singapur }\end{array}$ & $\begin{array}{c}\text { Australia } \\
\text { Japón } \\
\text { Nueva Zelanda }\end{array}$ \\
\hline Europa & $\begin{array}{c}\text { Alemania } \\
\text { Austria } \\
\text { Bélgica } \\
\text { Dinamarca } \\
\text { España } \\
\text { Francia } \\
\text { Italia } \\
\text { Países Bajos } \\
\text { Reino Unido } \\
\text { Suecia } \\
\text { Suiza }\end{array}$ & $\begin{array}{l}\text { UE-15 (excepto } \\
\text { Portugal) } \\
\text { Islandia } \\
\text { Noruega } \\
\text { Suiza }\end{array}$ & $\begin{array}{c}\text { UE-15 (excepto Portugal, } \\
\text { Luxemburgo y Grecia) } \\
\text { Mónaco } \\
\text { Noruega } \\
\text { Suiza }\end{array}$ & $\begin{array}{l}\text { UE-28 } \\
\text { Islandia } \\
\text { Noruega } \\
\text { Suiza }\end{array}$ \\
\hline
\end{tabular}

Fuente: Elaboración propia a partir de Chase-Dunn, Kawano y Brewer (2000), Babones (2005), Dunaway y Clelland (2017), United Nations (2018). Se resaltan en negrita aquellos Estados cuya incorporación difiere entre clasificaciones. 


\section{Migraciones y agricultura}

Históricamente, el sector agrícola ha dependido de la movilidad de trabajadores de diversas geografías para el trabajo de la tierra (Molinero-Gerbeau y Avallone, 2016). Si en algunos territorios, como en el Sur de España (Márquez Domínguez, 2014), California (Janow y Gilmartin, 1941) o en Italia (Avallone, 2017), era común el desplazamiento de jornaleros pobres provenientes de regiones aledañas, en otros lugares y épocas históricas, dicho desplazamiento, adquirió otras formas, tanto forzadas, como el esclavismo durante la colonización, como indirectas, como la expulsión por desposesión (Araghi, 2009). La centralidad sistémica que ocupa la apropiación de comida barata en la reproducción del capitalismo (Moore, 2015) ha hecho determinante, en cada fase histórica de acumulación, el mantenimiento de una producción agrícola constante, donde, disponer de mano de obra para trabajar en ella se ha convertido en crucial, requiriendo cada apropiación de la frontera productiva, del diseño de mecanismos que permitan garantizarla (Molinero-Gerbeau y Avallone, 2016). En el periodo neoliberal, el predominio de las cadenas globales ha conllevado la articulación de múltiples mecanismos para el reclutamiento de trabajadores al sector agrícola, desde permitir su libre circulación en áreas de gran diferencial económico (como la UE), al diseño de programas de migración temporal (Molinero-Gerbeau, 2018a), entre otros.

Sin cuestionar dicho contexto, Mezzadra y Neilson (2017) consideraron que aquellas perspectivas que explicaban los procesos migratorios exclusivamente desde la óptica de las cadenas globales, tendían a ofrecer visiones excesivamente estructurales, que impedían identificar los importantes procesos de agencia que los propios migrantes despliegan dentro dichos movimientos. Esto es relevante pues «al no prestar debida atención a la constitución mutua de los elementos integrados y abstractos de la producción, los análisis de la cadena global de mercancías no pueden captar completamente los procesos plagados de conflictos a través de los cuales una variedad de actores sociales, incluyendo a los migrantes, responden a las demandas abstractas del mercado, tratando de cambiar las relaciones concretas en las cuales adquieren vida los tejidos sociales del trabajo, incluso aquellos más abstractos.» (Mezzadra y Neilson, 2017: 147)

Ciertamente, tal como señala Sayad (2010), para entender las migraciones como un hecho social total, es determinante no solo entender los contextos (históricos y políticos) de origen y destino, sino que también es indispensable entender las lógicas que los propios migrantes siguen para insertarse en esas dinámicas. Dicho de otra manera, sin entender las subjetividades y los proyectos autónomos de los propios actores involucrados en la dinámica social analizada, no es posible comprender el contexto en su totalidad.

La literatura ha tendido a explicar la inserción de los trabajadores migrantes en el sector agrícola y su aceptación de las lógicas imperantes en él, tradicionalmente caracterizadas por la explotación laboral, principalmente, en base al diferencial de salarios existente entre sus zonas de origen y destino (Simmons, 1991). Sin embargo, aunque este factor sea relevante, recientes estudios han ido dando cuenta de que se trata de una realidad más compleja.

Aunque los migrantes que trabajan en la agricultura del centro tienden a migrar para mejorar sus condiciones de vida, son otros muchos factores los que explican tanto su permanencia continuada en el tiempo, como la reproducción de este tipo de flujos. En ese sentido, la investigación realizada por Flynn y Kay (2017) en zonas rurales de Escocia, es muy relevante. Tras realizar numerosas entrevistas de campo, señalaron, por ejemplo, que una parte de los migrantes trabajando en esos contextos, se mantenían en ellos, más allá del salario, por aportarles tanto una estabilidad económica como social, que ellos percibían como un contexto de "normalidad", frente a la constante inseguridad social que decían experimentar en sus contextos de origen. Otros señalaban incluso el ambiente rural como bucólico, explicando que, además de ganar un salario más elevado que en sus países, este medio les ofrecía la oportunidad de desarrollar sus proyectos de vida en un contexto de su agrado.

Muy diferente de esta realidad es la que presenta, por ejemplo, el contexto agrícola del Sur de Italia, caracterizado por la híperexplotación, así como por la vulneración sistemática y generalizada de los derechos de los trabajadores (Avallone, 2017). En un contexto tradicionalmente señalado como "opresivo", sin embargo, es también determinante conocer la acción de los trabajadores migrantes para poder entender cómo se articulan dichos mercados laborales. En una investigación previa, analizando entrevistas realizadas en la Piana del Sele (Salerno) a trabajadores agrícolas migrantes de origen marroquí, señalé cómo la persecución de sus propios objetivos perso- 
nales explicaba su aceptación de la norma laboral imperante (Molinero-Gerbeau, 2018c). Conscientes de la explotación que sufren y de la vulneración sistemática que los patrones hacen de la ley laboral, los migrantes entrevistados explicaban que se mantenían dentro de esa estructura por ser la única oportunidad que tuvieron, primero para regularizar su condición administrativa a través del contrato de trabajo, y segundo, por ser la vía más directa que percibían para obtener el permiso de residencia indefinido. Esto último es determinante pues se trata de un requisito indispensable para poder realizar libremente otros trabajos en otros lugares, o incluso ir a otros países europeos, pues el sector agrícola, en numerosos casos, no es más que un sector de paso de los migrantes dentro de sus itinerarios vitales. Tanto las lógicas expuestas por Flynn y Kay (2017), como éstas, son cruciales para entender los contextos analizados, pues muestran que los procesos de agencia de los trabajadores involucrados son determinantes para comprender la conformación de la realidad macro-estructural y, sobre todo, la reproducción social de la mano de obra involucrada.

Desplegando sus proyectos personales, los migrantes se erigen también en agentes de transformación social contribuyendo a la mutación tanto de los espacios en los que se insertan, como de sus lugares de origen. Diversas investigaciones han señalado cómo la llegada de extranjeros a estos medios rurales puede suponer una oportunidad de revitalización de los mismos (Sampedro y Camarero, 2016; Rye y Scott, 2018) y también cómo, principalmente aquellos que practican la migración circular (Macías Llaga et al., 2016), pero de igual manera quiénes transmiten remesas, tanto económicas, como sociales (Grabowska y Engbersen, 2016) contribuyen a transformar sus espacios de origen. En otros casos, directamente, la organización de los trabajadores liderando huelgas, protestas $u$ otros tipos de formas de resistencia (Perrotta, 2015) ha modificado de forma definitiva las condiciones laborales imperantes en los contextos donde se han producido. Incluso un dispositivo estatal tal como la puesta en marcha del programa de contratación de trabajadoras temporeras en Huelva, parte, entre otras razones, como una respuesta de los empresarios y el gobierno a las protestas de los trabajadores agrícolas migrantes (Gualda Caballero, 2012).

En definitiva, las dinámicas señaladas muestran que, tal y como exponen Mezzadra y Neilson (2017), la articulación y el funcionamiento de las cadenas agrícolas globales no pueden comprenderse en su complejidad sin incorporar al análisis los procesos de subjetivización de los trabajadores migrantes cuyo ejercicio de agencia implica una acción transformadora fundamental.

\section{ESTUDIOS DE CASOS}

\section{Metodología}

A continuación, se presentarán los estudios de casos con el objetivo de determinar la existencia de procesos de "migrantización" de la mano de obra en sus sectores agrícolas. La comparación que se llevará a cabo, permitirá no solo dimensionar este fenómeno, sino también inferir si se trata de una dinámica común al centro de la ecología-mundo. Se ha considerado que la metodología del estudio comparado de casos es adecuada pues permite la identificación de una dimensión concreta en un número limitado de casos (Caramani, 2008). Así, siguiendo la clasificación aportada por Chase-Dunn et al. (2000), que presenta casos muy diferentes entre sí, pero unidos por un elemento común (ser parte del centro de la ecologíamundo), se puede aplicar el denominado método comparativo del sistema más disímil, con el objetivo de comprobar si la dimensión investigada (la "migrantización" de la mano de obra agrícola) es recurrente, mostrando así una correlación entre ambas variables (Caïs, 1997).

La existencia o ausencia de procesos de "migrantización" de la mano de obra agrícola en los casos presentados vendrá determinada por las fuentes estadísticas de las que cada uno disponga. Así, mientras que en algunos de ellos se utilizarán datos de encuesta, en otros, los datos empleados provendrán de registros, como por ejemplo, el número de visados emitidos. La heterogeneidad de las fuentes estadísticas empleadas tiene que ver, por un lado, con la forma en la que cada Estado ha producido datos sobre esta dinámica y, por el otro, la diversidad de datos de diferente índole, servirá para poder ilustrar el proceso de la forma más completa y compleja posible ${ }^{5}$.

En las siguientes subsecciones podrán encontrarse los diversos estudios de casos. Cabe señalar que la organización de los mismos por bloques regionales obedece a un mero criterio organizativo, puesto que la pertenencia a una región concreta no determina que un Estado sea parte o no del centro global (Wallerstein, 2000). Por esta razón, no se realizarán com- 
paraciones intra-regionales, sino que los resultados del análisis de cada caso vendrán discutidos al final de los mismos, sirviendo la sección final de conclusiones, como discusión global de la comparación de todos ellos.

\section{Áreas centrales americanas: Estados Unidos y Canadá}

\section{Estados Unidos}

Los Estados Unidos de América presentan no solo uno de los casos más antiguos de "migrantización" de su sector agrícola, sino también de mayor incidencia del fenómeno. Aunque ya hay indicios de presencia migrante en los campos (principalmente de California) antes de los años 40 (Janow y Gilmartin, 1941), podemos situar el inicio de las actuales dinámicas en 1942, cuando se firma el primer PMT entre México y los Estados Unidos, conocido como el programa Bracero, que duró hasta 1964, tiempo en el que se firmaron 4,5 millones de contratos (Calavita, 1992; Mandeel, 2014).

La lógica del programa Bracero fue idéntica a la del resto de PMT que después le seguirán en otros casos nacionales (si bien cada programa tiene sus propias especificidades): se trata de un mecanismo legal, articulado en un tratado bilateral entre el Estado de origen y el de destino, que permite reclutar mano de obra extranjera durante un periodo acotado de tiempo tras el cual, retornar es obligatorio. Los permisos otorgados son estrictamente temporales no permitiendo su conversión a otros tipos e impidiendo que los trabajadores vengan acompañados de sus familias (Molinero-Gerbeau, 2018a).

Si bien, desde el punto de vista empresarial, la experiencia fue un éxito, el programa cayó tanto por los abusos detectados, que hicieron que México desestimara prolongarlo, como, principalmente, por el aumento del número de trabajadores irregulares empleados en el sector. Como explica Mandeel (2014) desde el 46 empezó a ser cada vez más habitual ver trabajadores irregulares en los campos, que, pese a convivir con los braceros, hacían las mismas tareas a un menor precio. Esto hizo que los empresarios agrícolas estadounidenses empezaran a priorizar este tipo de mano de obra hasta el punto de que el propio programa dejó de ser rentable para ellos.

En 1952 se crea otro PMT, denominado como H2A, que, a diferencia del Bracero, no estaba gestionado

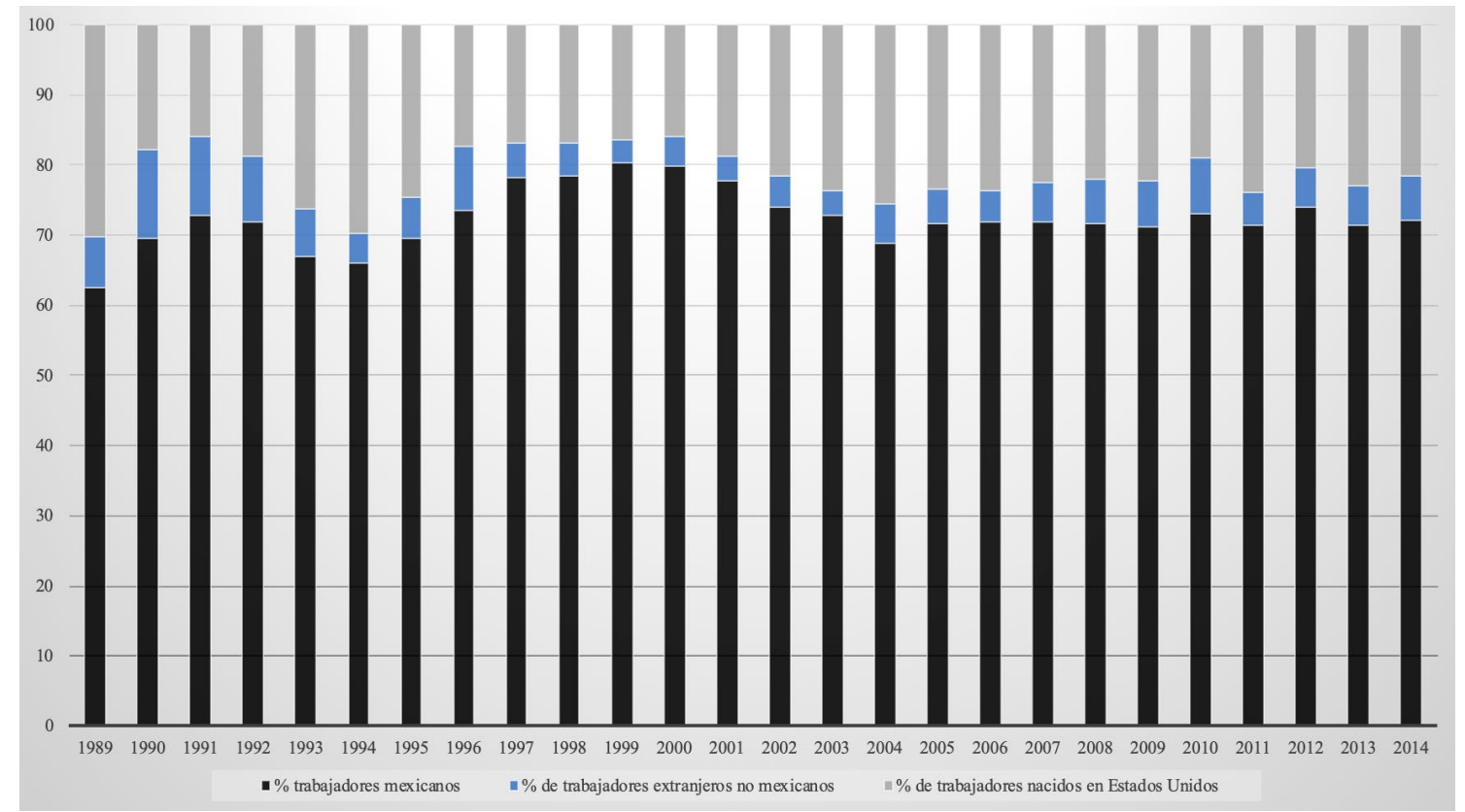

Fuente: National Agricultural Workers Survey (NAWS). 
con los países de origen, sino que simplemente abría la posibilidad a los empresarios agrícolas de contratar trabajadores extranjeros, sin límite de cuota anual, siempre que pertenecieran a uno de los países incluidos en el listado oficial. Este programa, a diferencia del Bracero, tuvo un impacto muy reducido, pues hasta 1990 no superaba las 10.000 llegadas por año, un hecho que viene explicado por las mismas razones que impulsaron la caída de su predecesor: los empresarios priorizaron la mano de obra irregular (Martin, 2017).

La literatura sugiere que en las subsiguientes décadas se ha dado un creciente fenómeno de "migrantización" de la mano de obra agrícola en Estados Unidos, pero ¿en qué magnitud? Para medirlo, disponemos de la National Agricultural Workers Survey (NAWS), una encuesta anual que viene realizándose desde 1989 y que permite ver, entre otros, el origen nacional de los trabajadores agrícolas en Estados Unidos. Es importante destacar que no incluye datos sobre trabajadores $\mathrm{H} 2 \mathrm{~A}$.

Como puede verse en la figura 1, aunque con fluctuaciones, desde 1989, al menos el $70 \%$ de la mano de obra total en la agricultura de Estados Unidos había nacido fuera del país, mostrando un nivel muy elevado de "migrantización" del sector.
En cuanto a la composición nacional de esta mano de obra, la encuesta NAWS muestra un claro predominio de trabajadores mexicanos, representando estos en torno, también, al $70 \%$ de la mano de obra total (en un arco donde, en algunos años, han rondado el $60 \%$ y en otros, el $80 \%$ ) tal y como muestra la figura 1 . Si atendemos a la incidencia de estos trabajadores dentro del colectivo de migrantes, los datos arrojan que, a lo largo del periodo analizado, algo más del $90 \%$ del total de trabajadores extranjeros han sido de origen mexicano desde 1993 hasta 2014 (con la excepción de 1996 donde representaron el $89,06 \%$ del total de extranjeros).

Respecto al programa $\mathrm{H} 2 \mathrm{~A}$, los datos públicos presentan un histórico también relativamente reciente, empezándose a registrar el número de visados emitidos desde 1997. La figura 2 muestra un fuerte crecimiento de este tipo de migración que pasó de estar por debajo de los 20.000 visados en 1997 a los más de 160.000 emitidos en 2017 , lo que supone que en 20 años el programa multiplicara por 8 el número de visados emitidos.

Como puede observarse, los números permanecen relativamente estables entre 1997 y 2005, empezando a mostrar una tendencia creciente a partir de 2007 $y$, sobre todo, aumentando fuertemente en 2011. Las

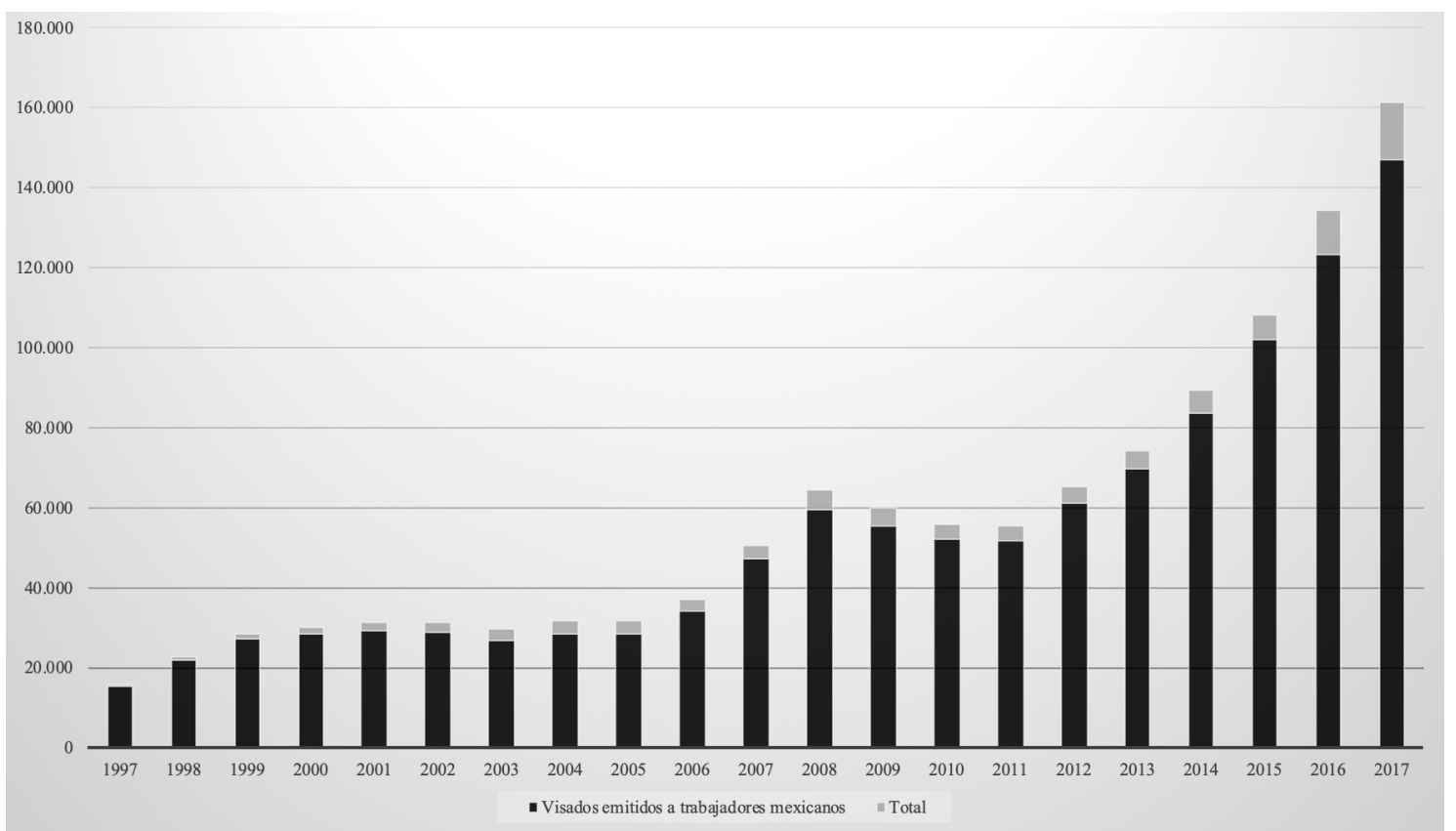

Fuente: US Department of State, Bureau of Consular Affairs (2019) 
razones, según Philip Martin (2017), tienen que ver con la crisis económica que hizo de Estados Unidos un destino menos atractivo para los mexicanos, lo que, unido al endurecimiento de los controles fronterizos y al hecho de que México experimentara un periodo de bonanza económica, redujo las llegadas de migrantes irregulares, obligando a los empresarios a acudir al programa. Otro factor a tener en cuenta, es que parte de los empleados que llevaban décadas trabajando en las haciendas envejecieron y se jubilaron o regresaron a origen, lo que hizo que los empresarios, ante la pérdida de parte de esta mano de obra hasta entonces estable, recurrieran al programa $\mathrm{H} 2 \mathrm{~A}$ para garantizarse la disponibilidad de trabajadores.

En cuanto a la composición nacional de los trabajadores $\mathrm{H} 2 \mathrm{~A}$, como muestra la figura 2, existe, al igual que en la mano de obra permanente, un absoluto predominio de trabajadores de origen mexicano, siendo estos, en el periodo registrado, siempre más del $90 \%$ de la mano de obra (salvo en 2005, que fueron un $89,6 \%$ del total).

Por último, en lo referente a las cifras de trabajadores indocumentados, cabe señalar que también vienen registradas en el NAWS, por lo que los datos podrían ser bastante fiables, al no reflejar solo a aquellos trabajadores con un permiso y un contrato legal. En cualquier caso, es relevante señalar que según Farmworker Justice (2014), una ONG dedicada a proteger los derechos de los trabajadores agrícolas migrantes, si bien el NAWS refleja que un $48 \%$ de los trabajadores encuestados está en situación irregular, la realidad podría alcanzar incluso al $70 \%$ de la mano de obra, siendo en cualquier caso cifras muy elevadas.

Así pues, el caso de Estados Unidos es claro. La "migrantización" (o "mexicanización", dado el absoluto predominio de este colectivo nacional sobre el resto) de la mano de obra de su sector agrícola se ha convertido en un fenómeno estructural, pues al (aproximado) $70 \%$ de la mano de obra permanente de origen migrante ya estabilizado en el tiempo, se une el fuerte crecimiento del programa $\mathrm{H} 2 \mathrm{~A}$ año tras año.

\section{Canadá}

El caso canadiense pese a presentar algunas similitudes con el estadounidense, por ejemplo, al disponer de un PMT de largo recorrido, es sustancialmente diferente. Para comprender las disimilitudes con su vecino, hay que atender sobre todo al hecho de que el tipo de producción (principalmente si es permanente o estacional) determina también el tipo de trabajo agrícola a realizar y por lo tanto la necesidad de una mayor o menor cantidad de mano de obra extranjera (Molinero-Gerbeau y Avallone, 2016). Si bien Canadá dispone de un dinámico sector agrícola, la situación geográfica del país, con una estación invernal larga y dura, condiciona el tipo de producción y sobre todo en qué momentos del año llevarla a cabo (Campbell et al., 2014), por ello, existe un predominio de la producción estacional en los meses con temperaturas más elevadas. Ello hace prever que el número de trabajadores migrantes de tipo permanente sea muy reducido, como sucede en otros enclaves puramente estacionales como, por ejemplo, el de Huelva (España) (Márquez Domínguez, 2014).

Los datos sobre trabajadores permanentes en la agricultura canadiense están disponibles en el Canadian Census of Agriculture, si bien solo el de 2016 (hasta la fecha actual, el último publicado) desagrega por nacionalidades y, como muestra la tabla 2, el porcentaje de extranjeros en este colectivo, es muy reducido, siendo el $92,44 \%$ de origen canadiense. Además, el resto de nacionalidades, que unidas no alcanzan más del 7,56\%, muestra una distribución que presenta una mayoría de países del centro global, lo que indica que no se debe tratar de mano de obra barata proveniente de la periferia.

El fuerte componente estacional explica la relevancia que tiene el "Seasonal Agricultural Workers Program" (SAWP), considerado por numerosas instancias internacionales como un modelo de buenas prácticas (Horgan y Liinama, 2016) que ha influenciado otros programas en el mundo (López-Sala, 2016). Creado en 1966 tras un acuerdo con varios países del Caribe, principalmente Jamaica, y luego ampliado en 1974 a

TABLA 2

DISTRIBUCIÓN PORCENTUAL DE LA MANO DE OBRA AGRÍCOLA EN CANADÁ POR LUGAR DE NACIMIENTO EN 2016

\begin{tabular}{|c|c|c|c|c|c|c|c|c|c|c|}
\hline Canadá & Países Bajos & Estados Unidos & Reino Unido & India & Alemania & Suiza & México & China & Francia & Otros países \\
\hline $92,44 \%$ & $1,16 \%$ & $0,98 \%$ & $0,87 \%$ & $0,80 \%$ & $0,58 \%$ & $0,41 \%$ & $0,29 \%$ & $0,23 \%$ & $0,14 \%$ & $2,09 \%$ \\
\hline
\end{tabular}

Fuente: Canadian Census of Agriculture (2016) 
México, el SAWP ha ido creciendo exponencialmente desde su creación (Horgan y Liinama, 2016). Los datos que muestra la figura 3, reflejan que entre 2007 y 2016 ha crecido más de un $60 \%$, aportando ya más de 50.000 trabajadores cada año, lo que, considerando los datos del Canadian Census of Agriculture, sería un $16 \%$ de la mano de obra total empleada en agricultura. Este fuerte crecimiento, tiene que ver con la apuesta que hizo el gobierno conservador de Stephen Harper por promocionar una migración de tipo temporal y circular frente a la permanente (Horgan y Liinama, 2016).

En cuanto a la composición nacional de estos trabajadores. Lamentablemente, el IRCC no proporciona datos estadísticos desagregados para el programa agrícola en concreto, pero la Secretaría de Relaciones Exteriores de México sí que dispone de datos acerca del número de trabajadores que han participado en el programa desde 2001. Como muestra la figura 3, la curva ascendente acompaña la tendencia general comentada anteriormente, permitiendo observar que los trabajadores mexicanos participando en el SAWP son prácticamente la mitad de la mano de obra total contratada dentro del programa. Si bien no tenemos datos concretos, dado que el SAWP solo aplica a México y a algunas islas del Caribe, podemos intuir que el resto de la cuota viene copada por nacionales de esta última región.
Por último, en lo que respecta al empleo de trabajadores irregulares, la literatura sugiere que, contrariamente a la tendencia global (Molinero-Gerbeau y Avallone, 2016), su incidencia en el contexto canadiense es muy reducida, por lo que los datos presentados serían bastante fieles al contexto real (Preibisch, 2011).

Como puede verse mediante las estadísticas disponibles, el proceso de "migrantización" de la mano de obra agrícola canadiense es también un hecho. Si bien en este caso el número de trabajadores permanentes de origen migrante es muy reducido, atendiendo a las características estacionales de la agricultura de este país, podemos ver cómo mediante el SAWP no solo se recluta una importante parte de la mano de obra requerida, sino que los volúmenes de trabajadores participando en este programa no cesan de crecer en el tiempo.

\section{Áreas centrales de Asia-Pacífico: Australia, Nueva Zelanda y Japón}

\section{Australia}

A diferencia de los casos americanos, y en sintonía con el resto de casos que se presentarán a continuación (tanto de Asia-pacífico, como europeos), la pre-

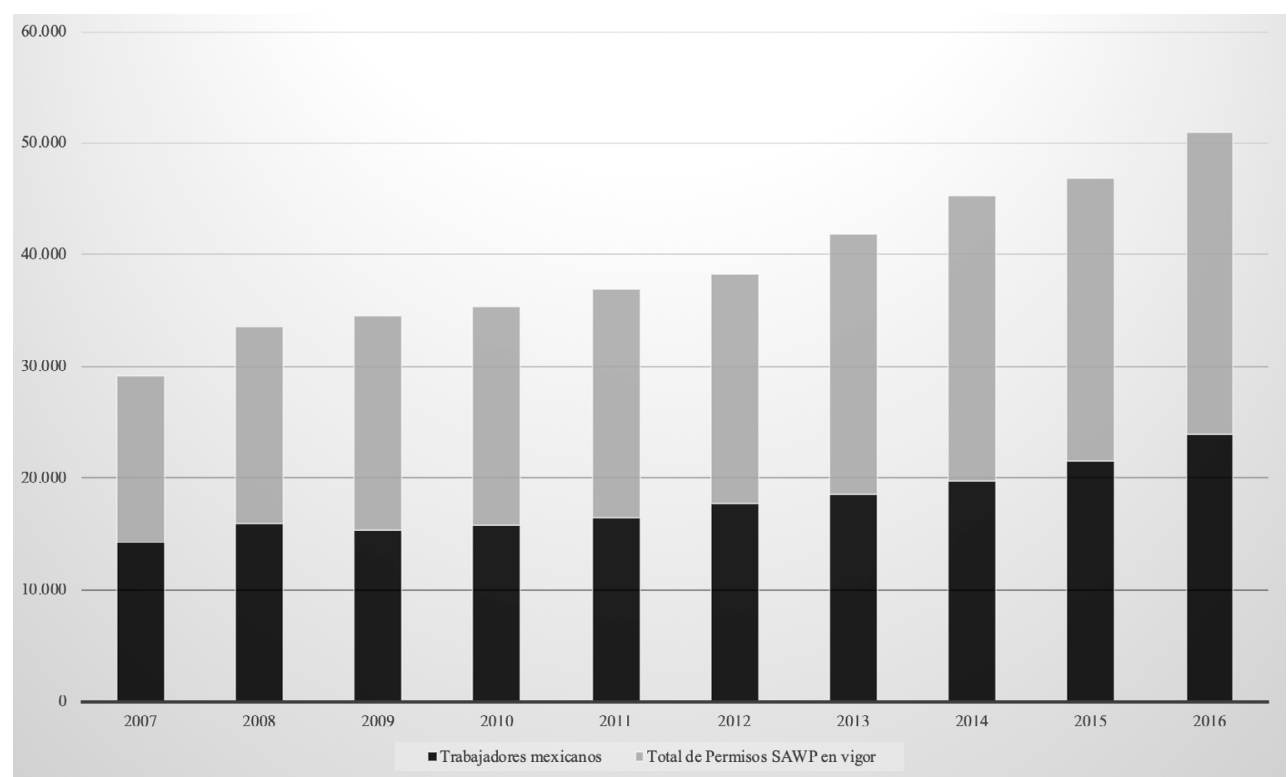

Fuente: Immigration, Refugees and Citizenship Canada (IRCC) (2019) y Secretaría de Relaciones Exteriores de México (2019). 
sencia de trabajadores migrantes en la agricultura australiana será tardía, iniciándose principalmente en los años 90 (Underhill et al., 2018). Las razones de la progresiva sustitución de trabajadores nacionales por migrantes estarán vinculadas a la baja remuneración y la temporalidad de un trabajo que, al igual que en Canadá, es eminentemente estacional (Curtain et al., 2018).

Underhill y Rimmer (2016) señalan que existen dos principales fuentes de provisión de trabajadores migrantes para la agricultura australiana, por un lado, los denominados "mochileros" ${ }^{6}$, es decir los jóvenes participantes en el programa de visados "Vacaciones - Trabajo", del que existen dos tipos, el visado 417 y el 462, y, por el otro, los migrantes indocumentados. Estos últimos por lo general son provenientes de países asiáticos, generalmente overstayers, es decir, que entran con un visado turista (u otro tipo) y prolongan su estancia por encima del periodo legal. En ambos casos, los trabajadores vienen canalizados al sector agrícola gracias a una compleja red de actores privados dedicados a la intermediación (Underhill et al., 2018).

La tercera vía de provisión de trabajadores migrantes para el sector primario australiano es su PMT, denominado como "Seasonal Worker Programme" (SWP), iniciado en 2008, al que se ha unido más recientemente, aunque con una previsible baja incidencia (está limitado a 2000 trabajadores por año), el "Pacific Labour Scheme", otro PMT inaugurado en 2018, que probablemente proveerá de trabajadores al sector agrícola, si bien es un programa abierto a todos los sectores laborales.

Este complejo panorama hace difícil cuantificar el fenómeno de la "migrantización" del sector (Underhill et al., 2018). Tanto para Underhill y Rimmer (2016) como para Curtain et al. (2018), en la actualidad, la mayoría de trabajadores agrícolas migrantes son mochileros. Este hecho dificulta la cuantificación del fenómeno, pues dicho visado se caracteriza por ofrecer a jóvenes de entre 18 y 30 años la posibilidad de residir un año en Australia tanto por vacaciones como para estudiar o realizar algún trabajo de tipo temporal. Pueden participar en este programa nacionales de 19 países, en el caso del visado 417, y de 23 en el caso del visado 462. Ambos incluyen nacionalidades tanto del centro (como Canadá, Italia, Estados Unidos o Japón) como de la periferia (Vietnam, Turquía, Malasia, etc.). La especificidad de este permiso radica en el hecho de no requerir tener una oferta de trabajo previa y, por lo tanto, no se puede saber

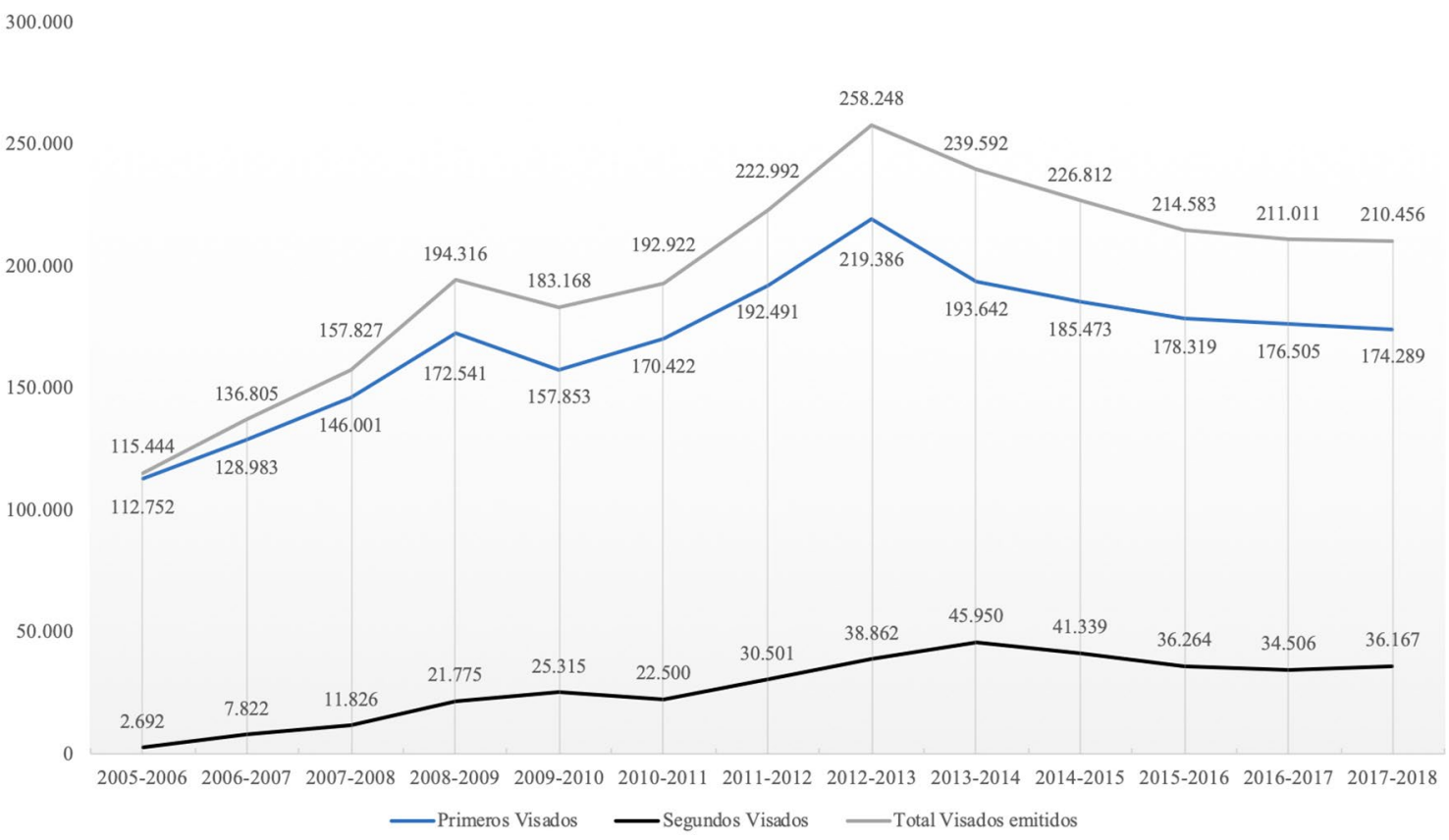

Fuente: Department of Home Affairs. Australian Government (2018). 
con exactitud cuántos de los participantes del programa han trabajado, ni mucho menos cuantos han realizado trabajo agrícola. La figura 4 muestra tanto el número de primeros y segundos visados 417 y 462 concedidos entre 2005 y 2018 como su evolución durante este periodo

Como puede observarse en el periodo mostrado, existe una tendencia creciente en la emisión de este tipo de visados, cuyo número se ha duplicado en poco menos de quince años, pero ¿cómo determinar cuántos de los participantes han trabajado en la agricultura? Por un lado, Underhill y Rimmer (2016) realizaron una encuesta no representativa a trabajadores agrícolas y mostraron que 4 de cada 5 respondientes tenían un permiso de este tipo. Además, dos estudios, realizados por Hay y Howes (2012) y por Doyle y Howes (2015), mostraron que en el primer caso un $73 \%$ de los empresarios agrícolas empleaban mochileros, cayendo esta cifra al $46 \%$ en el estudio realizado tres años después. Si bien estos datos muestran una tendencia decreciente (que puede explicarse por el recurso tanto a migrantes irregulares como a participantes en el SWP), permiten hacernos una idea del fenómeno.

Quizás el dato que permita identificar de forma más clara cuántos mochileros trabajan en la agricultura es el número de segundos visados. Las condiciones para obtener esta prórroga de otros 12 meses tienen que ver con haber realizado al menos 88 días de trabajo en los sectores específicos de subclase 462 , que son cuatro: agricultura y ganadería (en todo el territorio), pesca y perlado, cultivo y tala de árboles y turismo (estos tres últimos solo en la región norte del país). Según Underhill y Rimmer (2016) 90\% de los que obtuvieron un segundo visado hicieron trabajo agrícola. Así pues, si bien no puede cuantificarse con exactitud el número de mochileros realizando trabajo agrícola, sí podemos entrever que existe un progresivo proceso de "migrantización" del sector por la tendencia creciente del programa general y sobre todo del número de segundos visados.

En lo que respecta al SWP, se trata de un programa que copia al Recognised Seasonal Employer (RSE), el

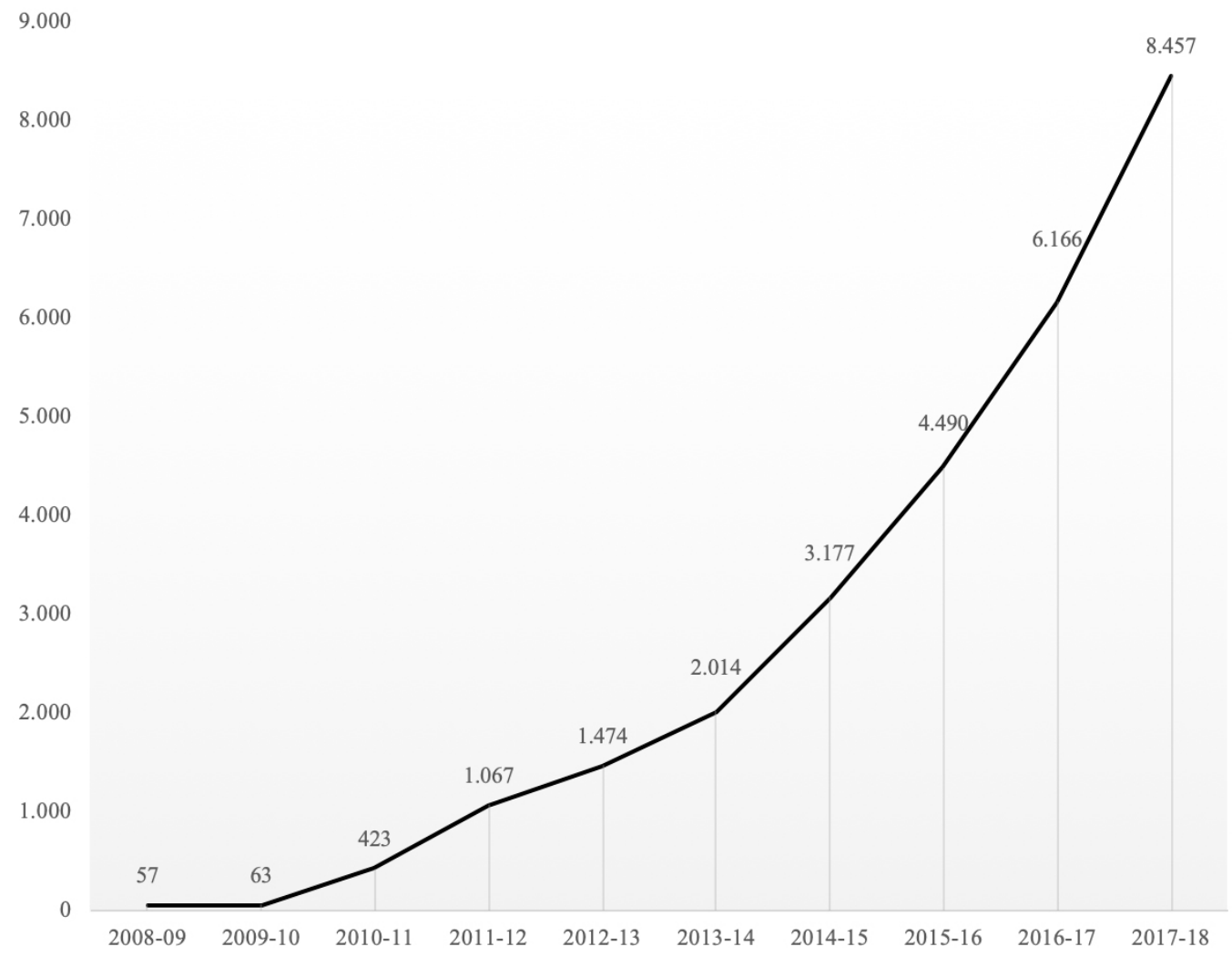

Fuente: Development Policy Centre (Devpolicy) (2019). 
programa neozelandés, que a su vez imitó el modelo del SAWP canadiense (Petrou y Connell, 2018). Este programa se inicia en 2008 , habiendo sido reivindicado durante años por parte de los empresarios e incluso habiendo sido recomendado por el Banco Mundial (Curtain et al., 2018). Sin embargo, el gobierno conservador de Howard era contrario a ello, de ahí que creara el segundo permiso de VacacionesTrabajo, para ejercer como un programa de facto que evitara así la implementación de uno nuevo. Será por tanto en 2007, con el cambio a un gobierno laborista, cuando esta posibilidad se abrirá. Como muestra la figura 5, los datos son claros, se trata de un instrumento en expansión a lo largo del tiempo.

Ciertamente las magnitudes son mucho más reducidas que en los programas americanos o incluso que las cifras de visados de Vacaciones-Trabajo, pues como muestran Curtain et al. (2018), hay un trabajador estacional proveniente del Pacífico por cada 10 mochileros. Aun así, no deja de ser relevante el exponencial crecimiento que el SWP ha experimentado en apenas una década, permitiendo entrever que, al coincidir en el tiempo con la caída del número de empresarios que emplean mochileros, podría poco a poco sustituir al anterior mecanismo.

En cuanto a la composición nacional de la fuerza de trabajo participante en el programa, puede verse, como muestra la tabla 3 , un absoluto predominio de las islas de Tonga y Tuvalu como principales lugares de origen (aunque con variaciones a lo largo del tiempo). El resto de participantes son también pertenecientes a islas del Pacífico (como Fiyi, Kiribati o Samoa), pues el SWP es un programa exclusivamente oceánico.

Por último, en cuanto a la mano de obra irregular, el Departamento de Inmigración y Ciudadanía Aus-

TABLA 3

DISTRIBUCIÓN PORCENTUAL DE VISADOS SWP EMITIDOS POR PAÍS DE ORIGEN ENTRE 2008 Y 2018

\begin{tabular}{|c|c|c|c|}
\hline Campaña agrícola & Tonga & Vanuatu & Otros \\
\hline $2012-13$ & 81,41 & 8,07 & 10,52 \\
\hline $2013-14$ & 74,33 & 10,53 & 15,14 \\
\hline $2014-15$ & 68,59 & 17,85 & 13,57 \\
\hline $2015-16$ & 58,44 & 26,68 & 14,88 \\
\hline $2016-17$ & 43,64 & 34,85 & 21,51 \\
\hline $2017-18$ & 32,99 & 39,59 & 27,42 \\
\hline
\end{tabular}

Fuente: Fuente: Development Policy Centre (Devpolicy) (2019) traliano (2011) estima que entre 40.000 y 93.000 trabajadores indocumentados trabajan con esta condición en Australia, de los cuales, según Underhill y Rimmer (2016), un tercio podrían hacerlo en agricultura, pudiendo alcanzar una cifra cercana a los 15.000 .

Con esta disparidad de números es complicado mostrar una imagen fiel a la realidad, si bien, el proceso de "migrantización" del sector agrícola australiano parece claro y constante en su crecimiento.

\section{Nueva Zelanda}

Aunque con sus inevitables especificidades, el caso neozelandés presenta numerosas similitudes con el australiano, fruto de una historia donde la influencia mutua ha sido una constante (Barry y Wailes, 2005).

Así, al igual que sucedió en su gigante vecino, el sector agrícola de Nueva Zelanda no empezará a depender del trabajo migrante hasta finales del siglo $X X$ y principios del XXI, abasteciéndose durante el periodo previo principalmente de trabajadores nacionales (tanto residentes locales como itinerantes) y, nuevamente al igual que Australia, de mochileros (Tipples, 2017). Solo hubo una excepción en este contexto, y fue la aplicación en los años 80 de un primer PMT de trabajadores agrícolas para hacer frente a una fuerte necesidad de mano de obra en ese periodo. Sin embargo, su corta duración en el tiempo tuvo que ver con el inicio de una crisis económica que volvió a nutrir al sector de trabajadores locales, conllevando el cierre del programa por parte de las autoridades (Petrou y Connell, 2018). No será hasta 2007 cuando el país, como ya se ha mencionado antes para el caso australiano, impulsado por el Banco Mundial, establecerá su PMT moderno, nombrado como "Recognised Seasonal Employer Scheme" (RSE).

A la hora de cuantificar la magnitud de la "migrantización" del sector agrícola de este país nos enfrentamos al mismo problema que en el caso australiano pues, por un lado, no podemos calcular de forma precisa cuántos mochileros realizan o han realizado trabajo agrícola. Nuevamente, quienes han tratado de arrojar la mayor luz posible sobre estas dimensiones han sido Curtain et al. (2018).

Al respecto de los mochileros, dichos autores estiman que en torno a un $29 \%$ de la mano de obra agrícola de este país se compone de este tipo de trabajadores, cuyas condiciones son idénticas a las australianas salvo por el hecho de que sólo realizando 
trabajo agrícola se puede solicitar el segundo permiso, que en este caso permite extender la residencia por tres meses y no por doce. La figura 6 muestra la evolución de este tipo de permisos.

Si bien los datos muestran una tendencia creciente, dada la incidencia moderada que tienen este tipo de permisos en el trabajo agrícola neozelandés, no es posible asegurar que dicho crecimiento esté vinculado al sector analizado. En el caso de los segundos permisos, la tendencia creciente sí está directamente conectada con el trabajo agrícola, pero como puede observarse, se trata de un crecimiento muy lento a lo largo del tiempo cuyo máximo pico tan solo alcanza los 4.108 permisos en 2016-2017 por lo que es prácticamente irrelevante. Aun así, como aseguran Curtain et al. (2018) la ratio de trabajadores agrícolas es de dos mochileros por cada participante en el PMT. En cuanto a la distribución nacional de estos trabajadores, no existen datos desagregados sobre segundos permisos y los primeros son tan difusos que es imposible determinar si existen especificas nacionalidades dedicadas al trabajo agrícola.
Por lo que respecta al programa RSE, los datos son mucho más claros, mostrando una tendencia creciente donde el número de participantes se ha multiplicado por tres en apenas diez años. La figura $7 \mathrm{da}$ cuenta de este fenómeno.

Respecto a la composición nacional de los participantes, si bien el RSE, a diferencia del SWP australiano, no es exclusivo del Pacífico, los nacionales de islas de esta región son predominantes, proviniendo aproximadamente el $40 \%$ de los participantes de Vanuatu, seguidos de Tonga y Samoa que abarcan entre el 15\% y el $20 \%$ del total de participantes según el año analizado.

Por último, respecto a la incidencia de la irregularidad en este contexto, Curtain et al. (2018) señalan que si bien en el pasado pudo tener algún tipo de relevancia y en la actualidad tampoco es descartable que existan algunos casos, son sin duda muy minoritarios, dada la prioridad que el gobierno neozelandés ha dado a la regulación del sector. Estos mismos autores afirman también que los propios «empresarios quisieron eliminar toda amenaza de mala publicidad

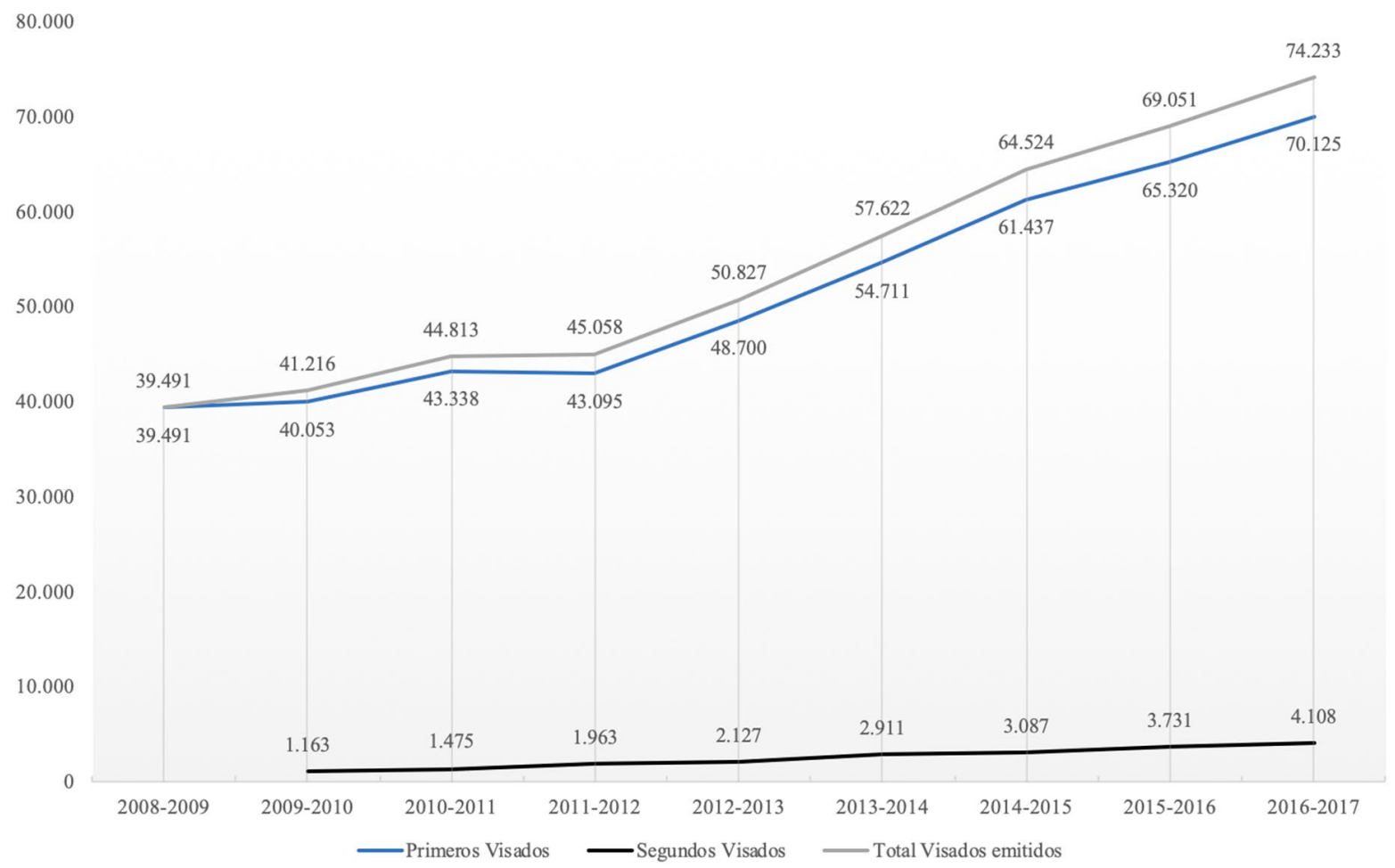

Fuente: New Zealand Immigration (2019) para los datos de primeros visados, los datos de Segundos visados provienen de Curtain et al. (2018). 
FIGURA 7

NÚMERO DE LLEGADAS POR AÑO EN EL RSE DURANTE EL PERIODO 2007-2018

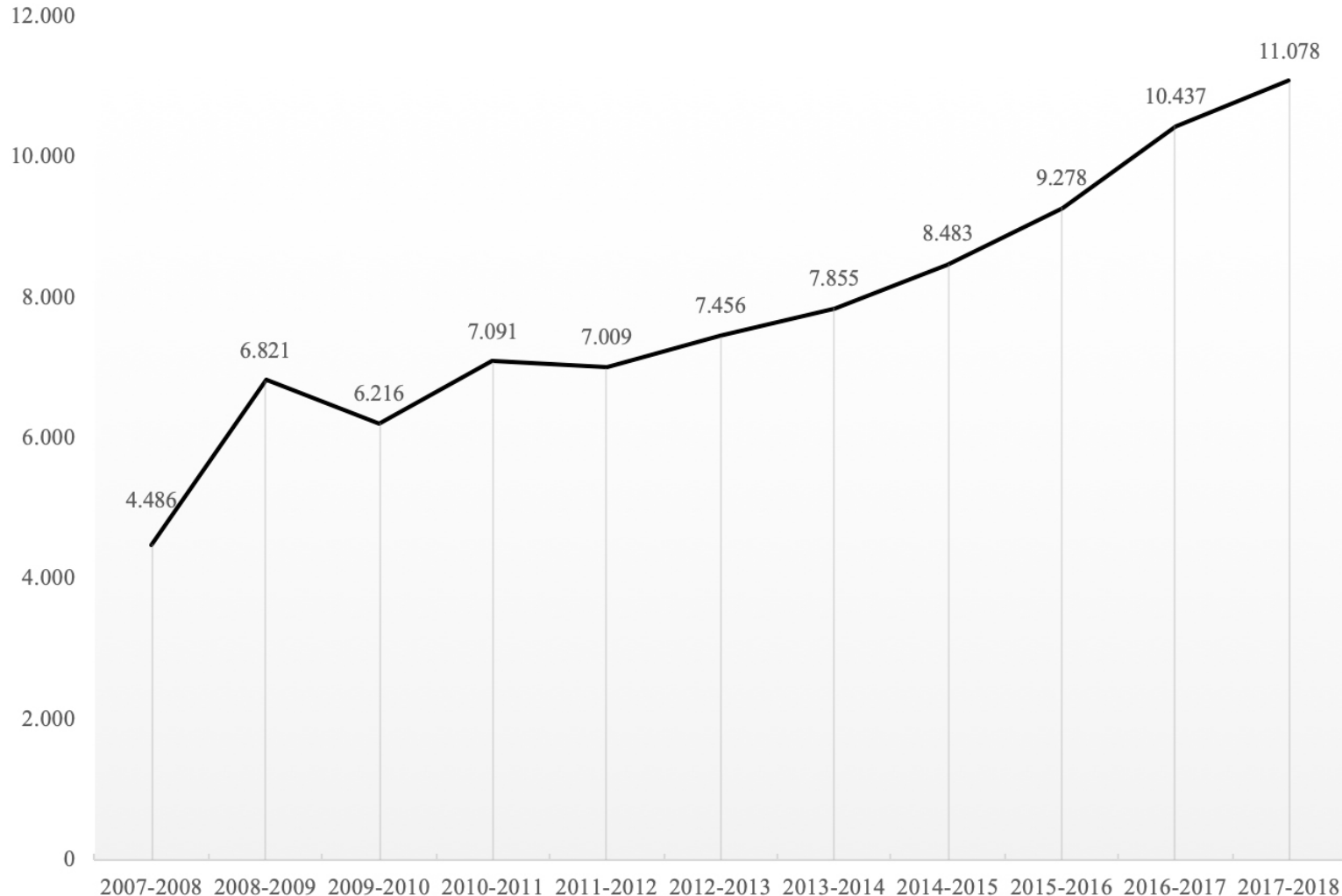

Fuente: New Zealand Immigration (2019).

a su comercio de exportación acabando con el uso de trabajadores ilegales y mejorando las condiciones de la mano de obra» (Curtain et al., 2018: 472) por lo que el no empleo de migrantes irregulares se puede explicar a causa de estrategias comerciales.

Nuevamente, al igual que en el caso australiano, intentar hacer una aproximación a la magnitud real de la "migrantización" del sector agrícola neozelandés es hartamente complicado, en este caso, principalmente, por no poder tener datos concretos sobre el número de mochileros empleados. Aun así, los datos muestran no solo una "migrantización" estructural, sino una expansión de la misma a lo largo del tiempo, tanto por el creciente uso de segundos visados de Vacaciones-Trabajo como por el exponencial crecimiento del programa RSE.

TABLA 4

DISTRIBUCIÓN PORCENTUAL DE LLEGADAS AL RSE POR PAÍS DE ORIGEN ENTRE 2007 Y 2018

\begin{tabular}{|c|c|c|c|c|c|c|c|c|c|c|c|}
\hline $\begin{array}{l}\text { Campaña } \\
\text { agrícola }\end{array}$ & $\begin{array}{l}2007- \\
2008\end{array}$ & $\begin{array}{l}2008- \\
2009\end{array}$ & $\begin{array}{l}2009- \\
2010\end{array}$ & $\begin{array}{l}2010- \\
2011\end{array}$ & $\begin{array}{l}2011- \\
2012\end{array}$ & $\begin{array}{l}2012- \\
2013\end{array}$ & $\begin{array}{l}2013- \\
2014\end{array}$ & $\begin{array}{l}2014- \\
2015\end{array}$ & $\begin{array}{l}2015- \\
2016\end{array}$ & $\begin{array}{l}2016- \\
2017\end{array}$ & $\begin{array}{l}2017- \\
2018\end{array}$ \\
\hline Vanuatu & 37,9 & 34,3 & 34,4 & 33,2 & 34,4 & 37,9 & 39,1 & 40,5 & 40,2 & 40,0 & 40,1 \\
\hline Tonga & 17,9 & 19,9 & 18,4 & 19,9 & 19,9 & 21,1 & 19,6 & 18,4 & 18,2 & 17,5 & 17,1 \\
\hline Samoa & 14,4 & 18,0 & 16,4 & 17,2 & 16,6 & 15,2 & 14,9 & 14,6 & 15,7 & 16,2 & 17,0 \\
\hline Otros & 29,8 & 27,8 & 30,8 & 29,7 & 29,1 & 25,7 & 26,5 & 26,5 & 26,0 & 26,4 & 25,8 \\
\hline
\end{tabular}

Fuente: New Zealand Immigration (2019). 


\section{Japón}

Pese a ser un caso relativamente desconocido para la literatura académica (al menos de aquella no publicada en japonés) el país nipón presenta no solo una serie de particularidades extremadamente interesantes, sino que converge con el resto de países del centro global al presentar importantes dinámicas de "migrantización" en su sector agrícola.

Japón es un país conocido por sus restrictivas políticas migratorias. Ya sea por el mito de la homogeneidad étnica que caracteriza a la cultura de la isla o por una extrema protección de su mercado laboral, el Estado japonés ha sido tradicionalmente reacio a la migración. Por ello, la ley de migraciones del país no reconoce ningún tipo de visado para trabajadores no cualificados, sin embargo, ciertas dinámicas sociodemográficas llevarán al Gobierno japonés a abrir en los 90, dos vías "no oficiales" a la migración. Una consistirá en crear un visado especifico para el retorno de los Nikkeijin, migrantes japoneses de tercera generación en Sudamérica. La otra consistirá en crear, en 1993, un programa de capacitación para "formar" a jóvenes de países asiáticos en determinadas profesiones, siendo el trabajo agrícola uno de los sectores privilegiados (Tian, 2018).

Las razones del progresivo relevo de parte de la mano de obra nacional por mano de obra migrante en la agricultura japonesa son similares a las de otros contextos: más del $40 \%$ de los trabajadores agrícolas nipones son ya mayores de 65 años, los jóvenes japoneses están cada vez menos interesados en realizar este trabajo y parte de la producción viene industrializándose por el avance de grandes empresas en el sector, lo que requiere emplear una creciente mano de obra (Ando y Horiguchi, 2013).

Este contexto generó una necesidad en el gobierno de explorar vías para reclutar trabajadores de su periferia sin por ello admitir el fin de las políticas migratorias restrictivas. Para ello, se puso en marcha el "Technical Intern Training Program" (TITP) que se dijo

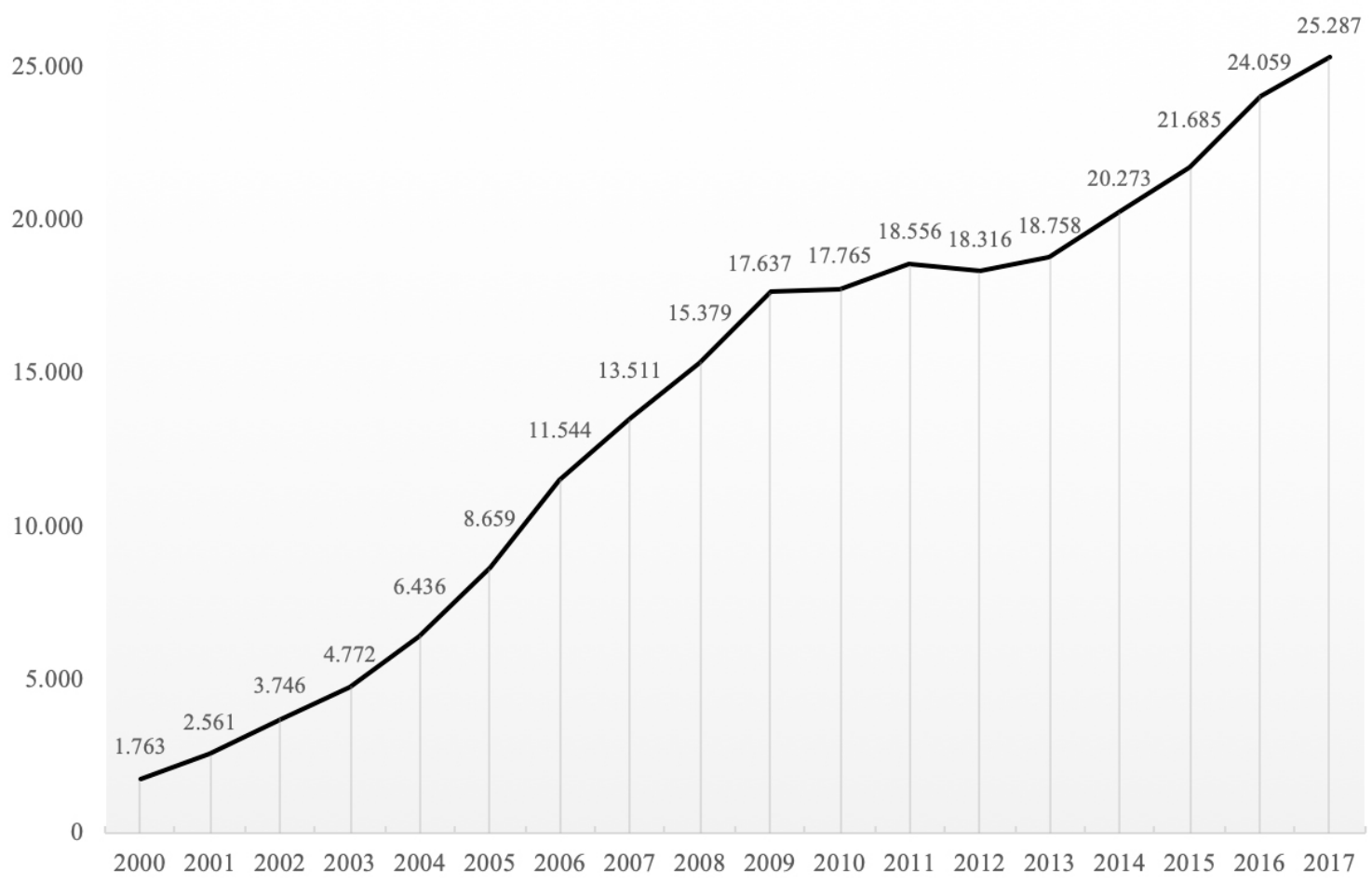

Fuente: Cálculo propio ${ }^{8}$ a partir de los datos de los Informes anuales de la Japan International Training Cooperation Organization (JITCO). 
en un principio que estaba diseñado para ayudar a jóvenes extranjeros a obtener habilidades laborales, pero que en la realidad se ha usado como un programa para contratar trabajadores no cualificados en la sombra (Satoshi, 2008).

Para los empresarios, el programa ha resultado ser un éxito pues ha permitido en gran medida compensar la necesidad de mano de obra pagando salarios bajos (Ando y Horiguchi, 2013), sin embargo, para los "aprendices"7 , tiene el problema de que son considerados como estudiantes y por ello, son remunerados por debajo del salario mínimo.

El programa empezó teniendo una duración máxima de tres años, siendo el primero (permiso tipo A) destinado a formarse, y por lo tanto conllevando la condición de estudiante, para en los dos siguientes (Tipo B) pasar a tener categoría de trabajadores. No todas las profesiones permiten extender el permiso hasta el segundo y tercer año, pero la agricultura, sí. Dado el éxito del programa y el aumento de la necesidad de mano de obra (tras los tres años, los trabajadores debían obligatoriamente regresar a sus países de origen) en 2017 el gobierno extendió el permiso hasta un máximo de 5 años. La figura 8 muestra la llamativa evolución del programa en los últimos 17 años.

Como puede observarse, el programa ha multiplicado casi por 15 el número de participantes entre el año 2000 y el año 2017. Además, con la extensión del permiso a 5 años, se prevé que esta tendencia alcista se mantenga en el futuro.

Respecto a la composición nacional de la mano de obra, lamentablemente existen muy pocos datos, pues los informes JITCO tan solo recogen esta información desde 2015 y solo para los permisos de tipo

TABLA 5

DISTRIBUCIÓN PORCENTUAL DE APRENDICES CON PERMISO TIPO B POR PAÍS DE ORIGEN PARA LOS AÑOS 2015-2017

\begin{tabular}{|l|c|c|c|}
\hline & $\mathbf{2 0 1 5}$ & $\mathbf{2 0 1 6}$ & $\mathbf{2 0 1 7}$ \\
\hline Vietnam & 26,8 & 33,2 & 36,0 \\
\hline China & 43,4 & 34,2 & 30,2 \\
\hline Filipinas & 10,4 & 10,8 & 11,2 \\
\hline Indonesia & 7,9 & 8,2 & 8,3 \\
\hline Otros & 11,5 & 13,7 & 14,2 \\
\hline
\end{tabular}

Fuente: JITCO (2018)
B. Aun así, la tabla 5 permite comprobar que existe, durante este período, un predominio absoluto de trabajadores vietnamitas y chinos, cuya suma supera ampliamente el $60 \%$ del total.

Para ver la importancia que tienen los aprendices dentro del total de la mano de obra empleada en la agricultura japonesa, podemos calcular el porcentaje que ocupan en función de las estimaciones de los diversos censos agrícolas recogidos por Shimizu (2017). La tabla 6 muestra una evolución notable, donde los aprendices que representaban un 6,19\% del total de la mano de obra agrícola japonesa en 2005, pasan a ser un $10,21 \%$ en 2010 y un $8,92 \%$ en 2015. La bajada entre 2010 y 2015 puede explicar la ampliación del permiso a 5 años impulsada dos años después.

Respecto al empleo de mano de obra irregular en el sector, puede afirmarse según Ando y Horiguchi (2013) que esta queda prácticamente descartada pues las penas que se aplican en estos casos son muy duras, yendo desde la obligación de reducir el tamaño de la empresa, a su propio cierre.

Así pues, los datos expuestos demuestran que Japón se inserta también, aunque de una forma muy particular, en la misma lógica que el resto de casos analizados. El proceso de "migrantización" de la agricultura japonesa es un hecho que se demuestra tanto cuantitativamente (por el exponencial crecimiento del empleo de aprendices) como cualitativamente, pues la extensión del permiso a 5 años es un claro indicio de que el Gobierno persigue mantener y ampliar la base de mano de obra agrícola proveniente del TITP. A todo ello cabe añadir un dato muy relevante, y es que, en 2014, el Gobierno japonés anunció que finalmente el país desarrollaría un PMT a imagen y semejanza de los que ya hemos visto en los casos prece-

TABLA 6

COMPOSICIÓN DE LA MANO DE OBRA AGRÍCOLA EN JAPÓN PARA LOS AÑOS 2005, 2010 Y 2015

\begin{tabular}{|l|c|c|c|}
\hline & 2005 & 2010 & 2015 \\
\hline $\begin{array}{l}\text { Mano de obra (temporal y } \\
\text { permanente) }\end{array}$ & 131.281 & 156.176 & 221.456 \\
\hline Número de aprendices & 8.659 & 17.765 & 21.685 \\
\hline $\begin{array}{l}\text { Mano de obra total (temporal, } \\
\text { permanente y aprendices) }\end{array}$ & 139.940 & 173.941 & 243.141 \\
\hline $\begin{array}{l}\text { Porcentaje de aprendices sobre } \\
\text { el total }\end{array}$ & $6,19 \%$ & $10,21 \%$ & $8,92 \%$ \\
\hline
\end{tabular}

Fuente: Shimizu (2017); Informes anuales JITCO. 
dentes. Finalmente, el nuevo programa, llamado "tokutei ginou" (Visado para Habilidades Específicas) se lanzó en abril de 2019, permitiendo obtener un permiso de cinco años de duración y con una cuota estimada para el primer año de entre 3.600 y 7.300 trabajadores para el sector agrícola, previéndose que en los primeros cinco años de programa vengan entre 18.000 y 36.500 trabajadores al sector. Dicho programa, que convivirá con el TITP, muestra que el proceso de "migrantización" del sector agrícola japonés es ya un fenómeno estructural y creciente.

\section{Áreas centrales de Europa: España e Italia en la Unión Europea}

Aunque en la sección 3 de este artículo se resaltó el hecho de que la clasificación aportada por ChaseDunn et al. (2000) no consideraba a toda la Unión Europea como una zona central de la ecología-mundo, las particularidades de esta área de libre comercio requieren un análisis específico. A lo largo del proceso de construcción europea, pero sobre todo desde que entró en vigor el Tratado de Maastricht en 1992, la Unión Europea ha generado una división internacional del trabajo entre sus Estados miembros. Así, en un proceso que se inició en los años 80 pero que conoció su mayor expansión en los 90, los Estados del sur de Europa, transformaron progresivamente sus sectores agrícolas al modelo industrial de tipo californiano, convirtiéndose en los principales productores y proveedores de frutas y hortalizas frescas del mercado único (Gertel y Sippel, 2014). Dentro de este bloque, sin duda, destacan Italia y España, que se convirtieron en los "huertos de Europa" (MolineroGerbeau y Avallone, 2018).

Dada esta particularidad, para nuestro estudio, no cabe analizar si se ha dado el fenómeno de la "migrantización" caso por caso en aquellos Estados europeos que figuran en el listado de Chase-Dunn et al. (2000), pues en realidad, una importante parte de los productos agrícolas consumidos en países como Reino Unido o Alemania, no viene producida en sus respectivos sectores nacionales, sino en España e Italia, principales exportadores de productos frescos a sus mercados (Van Rijswick, 2018). Esto rige también para Suiza, único Estado del listado que no pertenece a la UE, que se caracteriza por importar principalmente del área de la UE en torno al $40 \%$ de los alimentos que consume (OCDE, 2015). Pese a ello, numerosas investigaciones han dado cuenta de que también podría estar produciéndose el proceso de "migrantización" en estos Estados (Rye y Scott, 2018), pero para los objetivos de este artículo, se analizará como caso conjunto a España e Italia pues comparten una historia similar tanto en lo que se refiere a la evolución y composición de sus sectores agrícolas como en lo referente a sus dinámicas migratorias (Molinero-Gerbeau y Avallone, 2018).

Dado lo expuesto, en primer lugar, cabe resaltar que, históricamente, tal como señala la Comisión Europea (2019), la inmensa mayoría de las exportaciones de productos agroalimentarios de países de la UE se hacen dentro de la Unión, siendo menos de $1 / 3$ del total aquellos que se exportan fuera y, como puede verse en la tabla 7, España es el principal productor de hortalizas frescas, seguido de Italia, produciendo ambos más del $40 \%$ del total europeo.

TABLA 7

TONELADAS DE HORTALIZAS FRESCAS (INCLUIDOS MELONES Y FRESAS) PRODUCIDAS EN LA UE POR PAÍS EN 2016 Y 2017

\begin{tabular}{|l|c|c|c|c|}
\hline & $\mathbf{2 0 1 6}$ & \% sobre el total UE-28 & $\mathbf{2 0 1 7}$ & \% sobre el total UE-28 \\
\hline Unión Europea 28 & $65.878,01$ & 100 & $66.090,88$ & 100 \\
\hline España & $15.381,20$ & 23,35 & $15.400,38$ & 23,30 \\
\hline Italia & $12.760,46$ & 19,37 & $12.015,22$ & 18,18 \\
\hline Polonia & $5.841,87$ & 8,87 & $5.923,02$ & 8,96 \\
\hline Francia & $5.504,65$ & 8,36 & $5.606,67$ & 8,48 \\
\hline Países Bajos & $4.890,50$ & 7,42 & $5.405,18$ & 8,18 \\
\hline Alemania & $3.815,88$ & 5,79 & $4.087,71$ & 6,18 \\
\hline Grecia & $3.027,21$ & 4,60 & $2.853,38$ & 4,32 \\
\hline Otros Estados & $14.656,24$ & 22,25 & $14.799,32$ & 22,39 \\
\hline
\end{tabular}

Fuente: Eurostat [apro_cpnh1] (2019). 
La literatura sobre trabajo migrante en el sector agrícola de ambos países es muy rica y ha venido creciendo mucho en el último decenio (Gertel y Sippel, 2014; Corrado et al., 2017, Molinero-Gerbeau y Avallone, 2018) pero ¿en qué magnitud se ha dado el proceso de "migrantización" en ambos casos?

Si bien tanto para España como para Italia cabe señalar que existe, al igual que en Estados Unidos, un fuerte sector de trabajo permanente con producción continuada todo el año que convive con un importante sector de producción estacional, los mecanismos para satisfacer las necesidades de mano de obra han diferido en ambos casos. Así, mientras España diseñó un PMT (denominado como "contratación en origen") similar al modelo canadiense, pero cuya aplicación corresponde a las administraciones provinciales (López-Sala, 2016), Italia en cambio no optó por diseñar un PMT como tal, sino que estableció un permiso de trabajo estacional que individualmente podían solicitar los empresarios interesados (similar al H2A estadounidense, solo que limitado por una cuota anual). Aun así, ambos Estados han nutrido también su sector agrícola de mano de obra irregular (con mayor incidencia en el caso italiano) e intraeuropea, beneficiándose de la libre circulación de trabajadores en el área de la UE (Molinero-Gerbeau y Avallone, 2018).

Para obtener una fotografía lo más precisa posible de la mano de obra migrante empleada en el sector agrícola español disponemos de la Encuesta de Población Activa (EPA) realizada trimestralmente por el Instituto Nacional de Estadística (INE). Dicha encuesta tiene un largo recorrido histórico que permite fácilmente identificar la evolución experimentada en la composición de la mano de obra agrícola española. La figura 9, muestra un importante crecimiento en el número de migrantes activos en el sector agrícola entre 1987 y 2018.

Como puede verse, en los primeros diez años las cifras eran muy reducidas, pero a partir de 1997 se inicia un fuerte crecimiento, pasándose a estimar que en la actualidad hay unos 223.700 trabajadores extranjeros activos en el sector agrícola español, lo que representa en torno a un $7 \%$ del total nacional de

NÚMERO DE TRABAJADORES ACTIVOS DE ORIGEN EXTRANJERO EN EL SECTOR AGRÍCOLA ESPAÑOL ENTRE 1987 Y 2018 (MEDIA ANUAL)

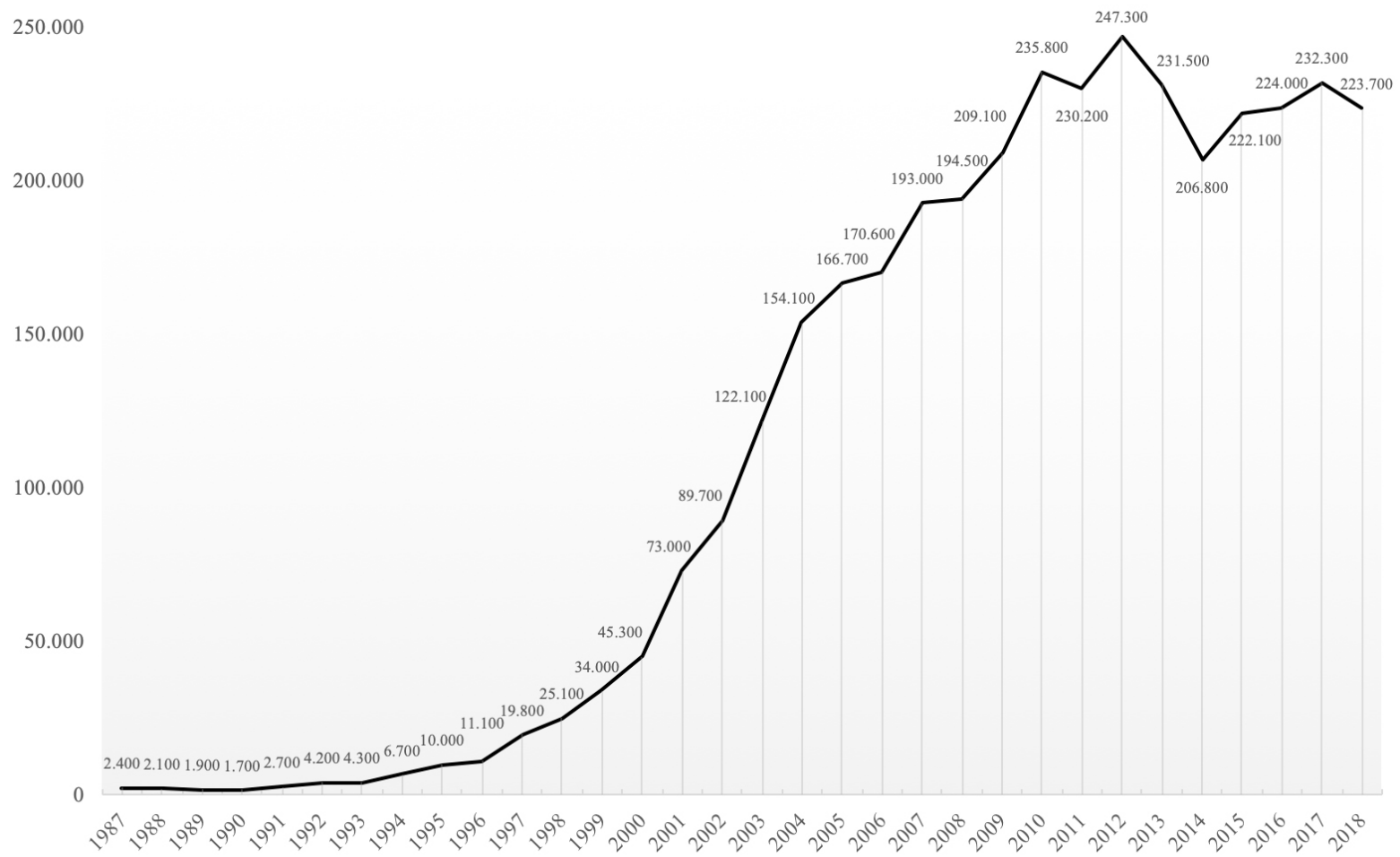

Fuente: Encuesta de Población Activa, INE (2019). 
activos en el sector. Si bien los datos nacionales agregados son muy contundentes, en aquellas provincias donde existe una producción estacional más fuerte, los datos de contratación son muy superiores (Molinero-Gerbeau, 2018b).

Respecto a la composición nacional de esta mano de obra, siempre según la EPA, se puede deducir que aproximadamente, de media, un tercio de estos trabajadores agrícolas provienen de la Unión Europea, en torno a un $20 \%$ provienen de Latinoamérica y en torno a un $40 \%$ del resto del mundo (presumiblemente de África Subsahariana y el Maghreb). Lamentablemente la EPA no viene desagregada por país de origen, solo por continente, pero la figura 10 al menos permite identificar de forma bastante clara esta composición.

El caso italiano arroja una tendencia similar. Si bien no es posible remontarse tan atrás en el tiempo como en el caso de la EPA española, los datos del Instituto de Estadística italiano (ISTAT) revelan de igual manera un fuerte crecimiento en el número de extranjeros empleados en el sector agrícola del país, tal y como muestra la figura 11.

Puede observarse que el proceso de "migrantización" de la mano de obra agrícola italiana es un he- cho, habiéndose casi multiplicado por cuatro el número de extranjeros empleados en el sector entre 2004 y 2018 . Si bien las magnitudes totales son inferiores a las que presenta España, cabe señalar que en el caso italiano la mano de obra migrante está estructuralizada en mayor medida, alcanzando en 2018 a ser el 17,7\% del total.

Respecto al trabajo estacional, si bien en ambos casos las cifras de trabajadores extranjeros contratados tanto con el PMT español como mediante los permisos estacionales italianos llegaron a ser relativamente relevantes antes de la crisis, en la actualidad los números son muy reducidos. Tanto el gobierno español, que congeló la contratación en origen (Molinero-Gerbeau, 2018b) como el italiano, que limitó la cuota anual de permisos estacionales (Molinero-Gerbeau y Avallone, 2018), apostaron por priorizar la contratación de nacionales y extranjeros ya residentes como medida para frenar el desempleo durante la crisis de 2008. Las cifras de Eurostat mostradas en la tabla 8 reflejan esta caída, si bien dan indicios, en el caso español, de un cierto repunte para el último año analizado.

Cabe señalar que estos datos incluyen todos los permisos emitidos por trabajo estacional, que, si

FIGURA 10

REGIÓN DE ORIGEN DE LA POBLACIÓN EXTRANJERA ACTIVA EN LA AGRICULTURA ESPAÑOLA DURANTE EL PERIODO 2005-2018

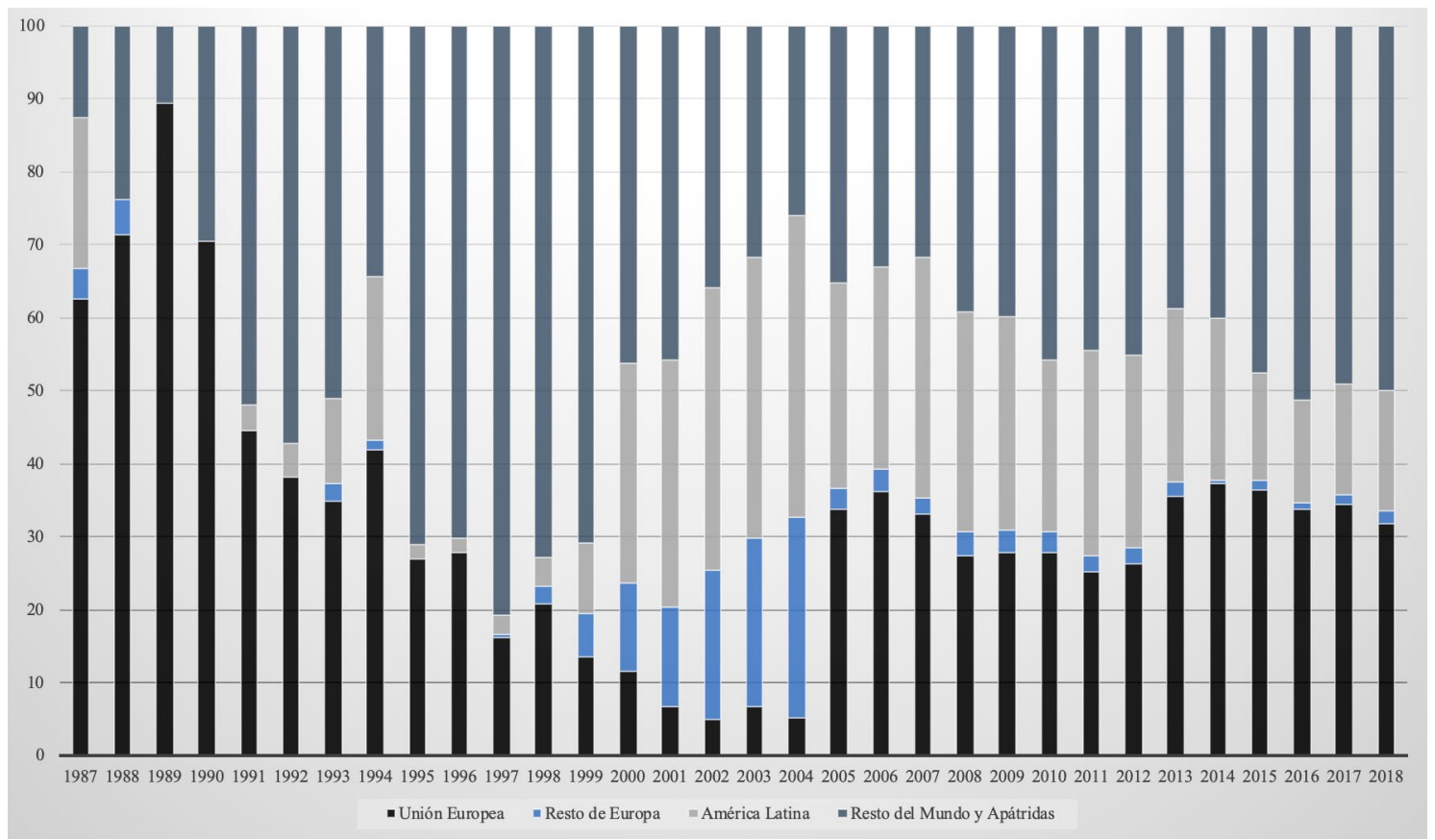

Fuente: Encuesta de Población Activa (EPA), INE (2019). 
FIGURA 11

NÚMERO TOTAL DE EMPLEADOS EXTRANJEROS EN AGRICULTURA, CAZA Y PESCA ENTRE 2004 Y 2007 Y EN AGRICULTURA, SILVICULTURA Y PESCA ENTRE 2007 Y 2018 EN ITALIA

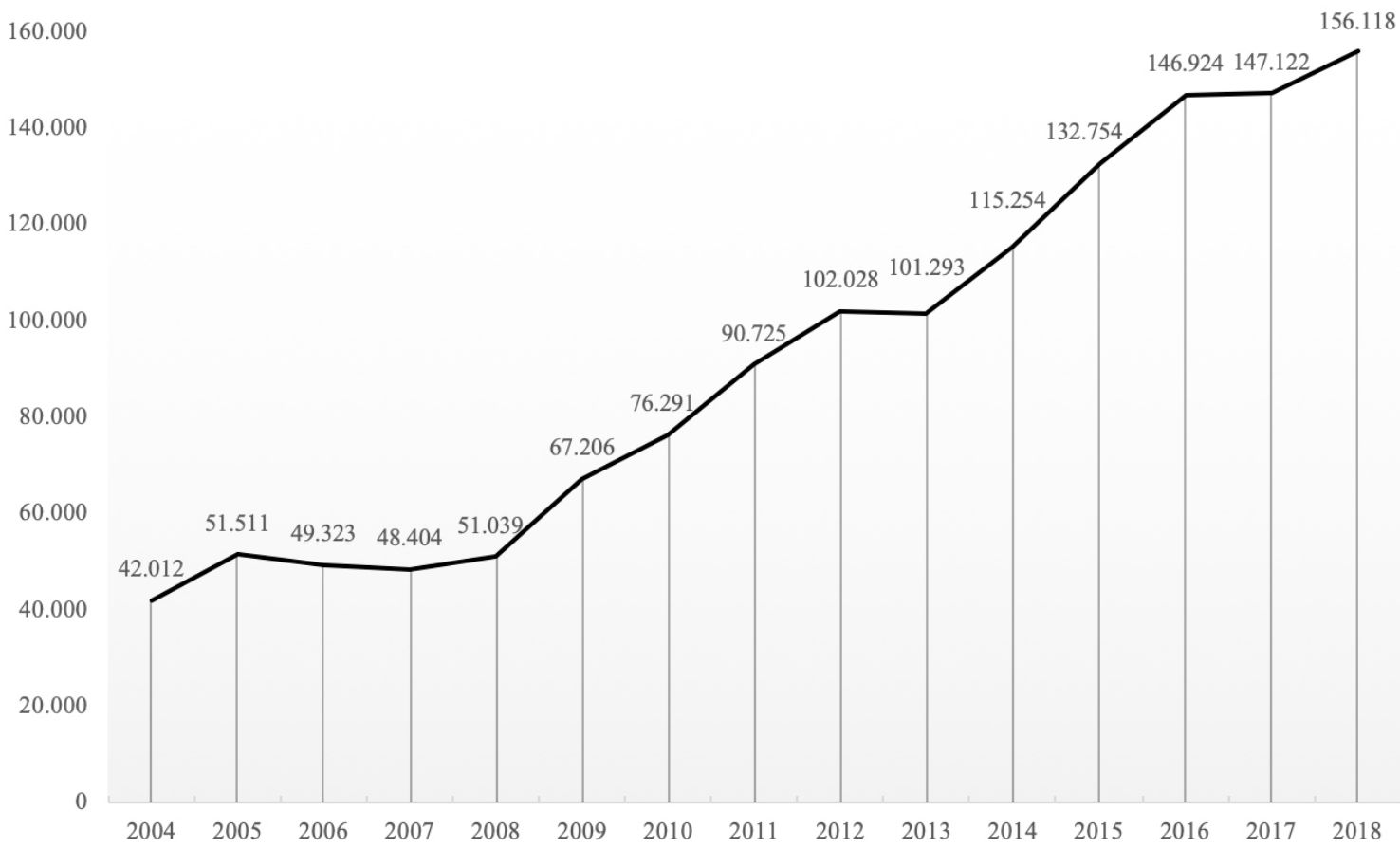

Fuente: Dataset Occupati, ISTAT (2019).

TABLA 8

NÚMERO DE PRIMEROS PERMISOS DE TRABAJO ESTACIONAL EMITIDOS A RESIDENTES DE TERCEROS PAÍSES EN ESPAÑA E ITALIA ENTRE 2008 Y 2017

\begin{tabular}{|c|c|c|c|c|c|c|c|c|c|c|c|}
\hline \multirow{7}{*}{ ESPAÑA } & & 2008 & 2009 & 2010 & 2011 & 2012 & 2013 & 2014 & 2015 & 2016 & 2017 \\
\hline & Total & 18.254 & 5.314 & 8.741 & 4.507 & 3.780 & 3.127 & 3.075 & 2.900 & 2.841 & 5.699 \\
\hline & Marruecos & 10.688 & 2.353 & 5.519 & 2.850 & 2.719 & 2.383 & 2.337 & 2.311 & 2.195 & 4.831 \\
\hline & Colombia & 2.924 & 1.525 & 1.608 & 894 & 601 & 464 & 436 & 366 & 450 & 654 \\
\hline & Perú & 460 & 204 & 235 & 57 & 47 & 27 & 18 & 19 & 21 & 54 \\
\hline & Ecuador & 1.463 & 527 & 559 & 166 & 112 & 93 & 74 & 81 & 61 & 53 \\
\hline & Otros & 2.719 & 705 & 820 & 540 & 301 & 160 & 210 & 123 & 114 & 107 \\
\hline \multirow{7}{*}{ ITALIA } & & 2008 & 2009 & 2010 & 2011 & 2012 & 2013 & 2014 & 2015 & 2016 & 2017 \\
\hline & Total & 8.423 & 23.034 & 22.345 & 15.204 & 9.715 & 7.560 & 4.805 & 3.570 & 3.520 & 3.593 \\
\hline & India & 1.856 & 3.951 & 3.470 & 3.270 & 1.898 & 1.596 & 1.110 & 901 & 943 & 1.108 \\
\hline & Albania & 1.416 & 4.452 & 4.086 & 2.371 & 1.550 & 1.176 & 908 & 696 & 952 & 971 \\
\hline & Marruecos & 1.743 & 4.601 & 4.210 & 3.249 & 1.814 & 1.606 & 868 & 513 & 523 & 483 \\
\hline & Ucrania & 251 & 718 & 774 & 539 & 420 & 283 & 168 & 127 & 152 & 191 \\
\hline & Otros & 3.157 & 9.312 & 9.805 & 5.775 & 4.033 & 2.899 & 1.751 & 1.333 & 950 & 840 \\
\hline
\end{tabular}

Fuente: Eurostat [migr_resocc] (2019). 
bien en su mayoría son para realizar trabajo agrícola, también pueden incluir trabajadores de otros sectores de tipo estacional, como el turismo. Respecto a la composición nacional de los trabajadores, en el caso español puede verse un claro predominio de migrantes marroquíes sobre el resto. En cambio, en Italia, el grueso lo ocupan los trabajadores de origen indio, albanés y marroquí, con variaciones a lo largo de los años, pero compartiendo magnitudes similares. Es importante destacar también en este caso que estos datos no revelan flujos de trabajadores estacionales intracomunitarios pues, al no necesitar un visado para moverse por la unión, no son registrados habitualmente por este tipo de estadísticas.

Por último, en lo que respecta a la incidencia de la irregularidad en los sectores agrícolas de ambos países, los contextos presentados son muy diversos. Si bien es cierto que numerosas investigaciones en España mencionan la relevancia de este tipo de trabajo (Corrado et al., 2017; Gertel y Sippel, 2014), también tienden a señalar que es un fenómeno relativamente residual en determinados enclaves, aunque quizás ello se deba a la ausencia de estimaciones nacionales. En el caso italiano, por el contrario, la incidencia del trabajo irregular en la agricultura ha sido notablemente señalada por la literatura producida en ese contexto (Colloca y Corrado, 2013) siendo varios los autores que aseguran que la irregularidad es un factor estructural en la producción agrícola de los diversos enclaves del país (Molinero-Gerbeau y Avallone, 2018). Para este contexto, sí existen determinadas estimaciones. En primer lugar, el INEA (Instituto Nacional de Economía Agraria) (2014) considera que en torno a un $12,2 \%$ de los trabajadores agrícolas en el país son irregulares. Sin embargo, por su parte, el ISFOL (Ente Público de Investigación sobre Temas de la Formación de las Políticas Sociales y del Trabajo) (2014) estima que la cifra es muy superior, pues podría alcanzar a un 41,6\% de los trabajadores agrícolas migrantes. Médicos sin Fronteras, por su parte, no hace una proyección nacional, pero en su informe de 2008 reflejaron que el $72 \%$ de los trabajadores migrantes entrevistados en su estudio no tenían un permiso regular (Medici Senza Frontiere, 2008) lo que revela que la irregularidad podría tener una incidencia aún mayor. Cabe señalar también que estas estimaciones se refieren exclusivamente a quienes no tienen un permiso de residencia en vigor, pues si se ampliaran los datos a quien sí dispone de ello, pero no de un contrato de trabajo formal, estaríamos ante cifras muy elevadas.
Así pues, los datos de los casos italiano y español son claros: pese a la crisis económica y la consecuente caída de la contratación de nacionales de terceros países por la vía del PMT o del visado estacional, el número de extranjeros contratados en sus respectivos sectores agrícolas no ha cesado de crecer, aumentando de forma progresiva la estructuralidad de dicha mano de obra. De esta manera, y al igual que en el resto de casos precedentes, es posible afirmar que, en las áreas centrales europeas, de las cuáles España e Italia son los principales productores y exportadores de frutas y verduras frescas, también se está produciendo el fenómeno global de la "migrantización" de la mano de obra agrícola.

\section{CONCLUSIONES}

Los casos presentados confirman de forma contundente la hipótesis planteada al inicio de este artículo, es decir, que la mano de obra agrícola en las áreas centrales de la ecología-mundo está experimentando un continuo y progresivo proceso de "migrantización". Si bien es cierto que no todos los casos presentan este fenómeno ni en las mismas condiciones, ni en las mismas magnitudes, todos ellos confirman el hecho de que la producción agrícola del centro global depende cada vez en mayor medida del trabajo migrante.

Siguiendo las teorías Estructuralistas, este proceso convergente puede ser interpretado según el momento en el que cada uno de los Estados mencionados se ubica dentro de la fase de acumulación actual (Arrighi y Moore, 2001). Así pues, el hecho de que los Estados Unidos iniciaran su conversión al modelo de agricultura industrial en una fase más temprana del capitalismo, explicaría la consistente estructuralidad del trabajo migrante en su sector agrícola. En cambio, otras economías cuya conversión a dicho modelo está siendo más tardía, habiéndose iniciado cincuenta años más tarde, como ha sucedido en los casos europeos y de Asia-Pacífico, estarían en una fase inicial dentro del irreversible proceso de "migrantización" de sus sectores agrícolas.

De acuerdo con los datos mostrados, es posible concluir que las áreas centrales identificadas por Chase Dunn et. al (2000) están experimentando (o han experimentado ya en gran medida) un proceso estructural de "migrantización" de la mano de obra de sus sectores primarios. Estas evidencias refuerzan la teoría de que, mientras se produce una nueva apro- 
piación de fronteras productivas, podría tratarse de un movimiento sistémico orientado a producir alimentos a bajo coste apoyándose en los bajos salarios de los migrantes (Molinero-Gerbeau y Avallone, 2016).

Convendría proseguir el análisis propuesto no solo para monitorizar la evolución en los próximos decenios de los casos aquí analizados, sino también para identificar la existencia de este mismo proceso en otras áreas centrales, ya sea de la clasificación aquí utilizada (por ejemplo, analizando más casos europeos) o también de otras clasificaciones (con casos como el de Israel, por ejemplo). Sin duda, un análisis pormenorizado de cadenas globales de producción de alimentos podría contribuir también a ver si el proceso de "migrantización" se ha producido de igual manera en eslabones productivos localizados en la periferia, pero cuyo fin de acumulación se sitúe en

\section{NOTAS}

1 En este artículo se escribirá el término "Estructuralismo" en mayúscula siguiendo la tradición de la disciplina de Relaciones Internacionales que busca, mediante esta práctica, diferenciar el empleo de términos políticos de la mención a paradigmas.

2 La clasificación aquí presentada figura en el Apéndice de dicho artículo

3 La clasificación del WESP denomina a los Estados del listado presentado como "Estados desarrollados", no como Estados del Centro

4 Las Regiones de Administración Especial (SARS por sus siglas en inglés) son dos regiones autónomas pertenecientes al Estado Chino que corresponden a las islas de Macao y Hong Kong.

\section{REFERENCIAS}

Ando, M. y Horiguchi, K. (2013). Japanese agricultural competitiveness and migration, Migration Letters, 10 (2), pp. 144-158.

Araghi, F. (2009). Accumulation by Displacement: Global Enclosures, Food Crisis, and the Ecological Contradictions of Capitalism. Review (Fernand Braudel Center), 32(1), pp. 113-146.

Arrighi, G. y Moore, J. W. (2001). Capitalist Development in World-Historical Perspective. En R. Albritton, M. áreas centrales. Como puede verse, existe un vasto terreno para extender las investigaciones en un campo de estudios que no deja de crecer.

\section{RECONOCIMIENTOS}

Quisiera agradecer a Takahiko Ueno de la Hitotsubashi University (Tokyo) por su inestimable ayuda tanto para obtener bibliografía y datos sobre el caso japonés, como por las necesarias explicaciones y traducciones que me ha aportado para entender los documentos utilizados en esta investigación.

Esta investigación ha sido financiada por la II Convocatoria de Contratos de Investigación "Ford España - Apadrina la Ciencia" con el apoyo del Ford Motor Company Fund.

5 Puede consultarse en el anexo de este artículo un listado completo de las fuentes estadísticas empleadas.

6 Los participantes en el programa de Vacaciones Trabajo (Working Holidaymakers) son denominados informalmente como backpackers (mochileros).

7 Los participantes en el programa son denominados como trainees es decir, aprendices.

8 Para el cálculo del número anual se sigue la fórmula empleada por Ando y Horiguchi (2013) es decir, que la cifra para cada año tiene en cuenta el número de aprendices con permiso $\mathrm{A}$ (primer año) sumada al número de aprendices con permiso $B$ (segundo y tercer año) tanto de ese año como del anterior.

Itoh, R. Westra y A. Zuege (Eds.), Phases of Capitalist Development. Booms, Crises and Globalizations (pp. 56-75). Nueva York, Estados Unidos: Palgrave.

Avallone, G. (2017). Sfruttamento e resistenze. Migrazioni e agricoltura in Europa, Italia, Piana del Sele. Verona: Ombre Corte.

Babones, S. J. (2005). The country-level income structure of the world-economy, Journal of WorldSystems Research, XI, pp. 29-55. 
Barry, M. y Wailes, N. (2005). Revisiting the AustraliaNew Zealand Comparison, New Zealand Journal of Employment Relations, 30 (3), pp. 1-17.

Boyd, M., Taylor, C. y Delaney, P. (1986). Temporary Workers in Canada: A Multifaceted Program, International Migration Review, 20 (4), pp. 929-950.

Brown, C. y Ainley, K. (2009). Understanding International Relations, Nueva York, Estados Unidos: Palgrave Macmillan.

Caïs, J. (1997). Metodología del análisis comparative, Madrid, España: CIS.

Calavita, K. (1992). Inside the State: The Bracero Program, Immigration and the I.N.S., Nueva York, Estados Unidos: Routledge.

Campbell, I. D., Durant, D. G., Hunter, K. L. y Hyatt, K. D. (2014). Food Production. En F. J. Warren y D. S. Lemmen (Eds.), Canada in a Changing Climate: Sector Perspectives on Impacts and Adaptation (pp. 99134). Ottawa, Canadá: Government of Canada.

Caramani, D. (2008). Comparative Politics, Nueva York, Estados Unidos: Oxford University Press.

Chase-Dunn, C., Kawano, Y. y Brewer, B. D. (2000). Trade Globalization since 1795: Waves of Integration in the World-System, American Sociological Review, 65 (1), pp. 77-95.

Colloca C. y Corrado A. (Eds.) (2013). La globalizzazione delle campagne. Migranti e società rurali nel Sud Italia, Milán, Italia: FrancoAngelli.

Comisión Europea (2019). Agricultural and food trade, Bruselas, Bélgica: CE.

Corrado, A., De Castro, C. y Perrotta, D. (2017). Migration and Agriculture. Mobility and change in the Mediterranean area, Londres, Reino Unido: Routledge.

Curtain, R., Dornan, M., Howes, S., y Sherrell, H. (2018). Pacific seasonal workers: Learning from the contrasting temporary migration outcomes in Australian and New Zealand horticulture, Asia \& the Pacific Policy Studies, 5 (3), pp. 462-480.

De Genova, N., Garelli, N. y Tazzioli, M. (2018). Autonomy of Asylum? The Autonomy of Migration Undoing the Refugee Crisis Script, South Atlantic Quarterly, 117 (2), pp. 239-265

Department of Immigration and Citizenship. (2011). Reform of employer sanctions (Howells Review) regulation impact statement. Belconnen. Australia: Gobierno Australiano. Disponible en: https://ris. pmc.gov.au/sites/default/files/posts/2012/01/03Reform-of-Employer-Sanctions-RIS.pdf [consultado el 18 de octubre de 2019]

Dunaway, W. A. y Clelland, D. A. (2017). Moving toward Theory for the 21st Century: The Centrality of Nonwestern Semiperipheries to World Ethnic/Racial Inequality, Journal of World-Systems Research, 23/2, pp. 400-464.

Doyle, J. y Howes, S. (2015). Australia 's Seasonal Worker Program: Demand -side Constraints and Suggested Reforms, Canberra, Australia: World Bank Discussion Paper.

Farmworker Justice (2014). Selected Statistics on Farmworkers, Washington D.C., Estados Unidos: Farmwoker Justice.

Gertel, J. y Sippel, S. R. (Eds.) (2014). Seasonal workers in Mediterranean agriculture: the social costs of eating fresh, Londres, Reino Unido: Routledge.

Grabowska, I., \& Engbersen, G. (2016). Social Remittances and the Impact of Temporary Migration on an EU Sending Country: The Case of Poland. Central and Eastern European Migration Review, 5(2), pp. 99-117.

Gualda Caballero, E. (2012). Migración circular en tiempos de crisis. Mujeres de Europa del Este y africanas en la agricultura de Huelva. Papers, 97(3), pp. 613-640.

Hay, D. y Howes, S. (2012). Australia's Pacific Seasonal Worker Pilot Scheme: Why has take-up been so low?, Canberra, Australia: Development Policy Centre discussion paper 17.

Horgan, M. y Liinamaa, S. (2016). The social quarantining of migrant labour: everyday effects of temporary foreign worker regulation in Canada, Journal of Ethnic and Migration Studies, 43 (5), pp. 713-730.

INEA (2014). Indagine sull'impiego degli immigrati in agricoltura in Italia. 2012, Roma, Italia: INEA.

ISFOL (2014). II lavoro sommerso e Irregolare degli stranieri in Italia, Roma, Italia: ISFOL.

Janow, S. J. y Gilmartin, W. (1941). Labour and Agricultural Migration to California 1935-40. Monthly Labor Review, 53(1), pp. 18-34.

King, G., Keohane, R. O. y Verba, S. (1994). Designing Social Inquiry. Scientific Inference in Qualitative 
Research. Princeton, Estados Unidos: Princeton University Press.

López-Sala, A. (2016). Induced circularity for selective workers. The case of seasonal labor mobility schemes in the spanish agriculture. Arbor, 192 (777), pp. 1-12.

Macías Llaga, I., Márquez Domínguez, J. A., \& Jurado Almonte, J. M. (2016). La contratación en origen de temporeros marroquíes para los campos españoles como experiencia de codesarrollo. Cuadernos Geográficos, 55(2), pp. 173-194.

Mandeel, E. W. (2014). The Bracero Program 19421964, American International Journal of Contemporary Research, 4 (1), pp. 171-184.

Márquez Domínguez, J. A. (2014). Jornaleros extranjeros en España. El contingente agrícola de temporada como política de control de los flujos migratorios, Huelva, España: Universidad de Huelva.

Martin, P. (2017). Immigration and Farm Labor: from unauthorized to H2A for some? Washigton D.C., Estados Unidos: Migration Policy Institute.

Mata Codesal, D. (2016). ¿Es deseable desmigrantizar nuestras investigaciones?, Ankulegi, 20, pp.47-60.

Medici Senza Frontiere (2008). Una stagione all'inferno. Rapporto sulle condizioni degli immigrati impiegati in agricoltura nelle regioni del Sud d'Italia. Roma, Italia: MSF.

Mezzadra, S. y Neilson, B. (2017). La frontera como método. Madrid: Traficantes de Sueños.

Molinero-Gerbeau, Y. (2018a). Programas de migración temporal ¿la utopía del pensamiento de Estado hecha realidad? En G. Avallone y E. Santamaría (Eds.), Abdelmalek Sayad: una lectura crítica. Migraciones, saberes y luchas (sociales y culturales) (pp. 279-295). Madrid, España: Dado Ediciones.

Molinero Gerbeau, Y. (2018b). La privatización de los programas de migración temporal en España como efecto poscrisis. En J. Arango, R. Mahía, D. Moya y E. Sánchez-Montijano (Eds.), Anuario Cidob de la Inmigración (pp. 284-206). Barcelona, España: Cidob.

Molinero Gerbeau, Y. (2018c). Ejerciendo agencia en las cadenas agrícolas globales. Del modelo boliviano en la agricultura argentina a la situación de los migrantes marroquíes en la agricultura de la Piana del Sele (Salerno, Italia), Theomai. Estudios
Críticos sobre Sociedad y Desarrollo, 38, pp. 68-90.

Molinero-Gerbeau, Y. y Avallone, G. (2016). Produciendo comida y trabajo baratos: migraciones $y$ agricultura en la ecología-mundo capitalista, $R e$ laciones Internacionales, 33, pp. 31-51.

Molinero-Gerbeau, Y. y Avallone, G. (2018). Migration and Labour Force needs in contemporary agriculture: what drives states to implement temporary programs? A comparison among the cases of Huelva, Lleida (Spain) and Piana del Sele (Italy), Calitatea Vietii, 29(1), pp. 3-22.

Moore, J. W. (2003). Capitalism as World-Ecology: Braudel and Marx on Environmental History, Organization \& Environment, 16 (4), pp. 431-458.

Moore, J. W. (2015). Capitalism in the Web of Life: Ecology and the Accumulation of Capital, Nueva York, Estados Unidos: Verso.

Moore, J. W. (2016). El fin de la naturaleza barata: o cómo aprendí a dejar de preocuparme por "el" medioambiente y amar la crisis del capitalismo, Relaciones Internacionales, 33, pp. 143-174.

OCDE. (2015). OECD Review of Agricultural Policies: Switzerland 2015, Paris, Francia: OECD Publishing.

Perrotta, D. (2015). Agricultural Day Laborers in Southern Italy: Forms of Mobility and Resistance, South Atlantic Quaterly, 114(1), pp. 195-203.

Petrou, K. y Connell, J. (2018). “We don't feel free at all": temporary ni-Vanuatu workers in the Riverina, Australia, Rural Society, 27 (1), pp. 66-79.

Preibisch, K. (2011). Migrant Workers and Changing Work-place Regimes in Contemporary Agricultural Production in Canada, International Journal of the Sociology of Agriculture and Food, 1 (19), pp. 62-82.

Van Rijswick (2018). World Vegetable Map 2018. More than just a local affair. Utrecht, Países Bajos: Rabobank - RaboResearch Food \& Agribusiness.

Rogaly, B. (2008). Intensification of workplace regimes in British horticulture: the role of migrant workers, Population, Space and Place, 14 (6), pp. 497-510.

Rye, J. F. y Scott, S. (2018). International Labour Migration and Food Production in Rural Europe: A Review of the Evidence, Sociologia Ruralis, 58 (4), pp. 928-952. 
Sampedro Gallego, R., \& Camarero Rioja, L. (2016). Inmigrantes, estrategias familiares y arraigo: las lecciones de la crisis en las áreas rurales. Migraciones, (40), pp. 3-31.

Satoshi, K. (2008). Japan's Internship Training Program for Foreign Workers: Education or Exploitation?, The Asia-Pacific Journal, 6 (7), pp. 1-8.

Sayad, A. (2010). La doble ausencia: de las ilusiones del emigrado a los padecimientos del inmigrado. Barcelona: Anthropos.

Simmons, A. B. (1991). Explicando la migración: la teoría en la encrucijada. Estudios Demográficos y Urbanos, 6(1), pp. 5-31.

Shimizu, T. (2017). Present state of Japanese agriculture and future prospect for agricultural structure: Detailed picture seen in 2015 Agricultural Census, Tokyo, Japón: Norinchukin Research Institute.

Tian, Y. (2018). Workers by any other name: comparing co-ethnics and 'interns' as labour migrants to Japan, Journal of Ethnic and Migration Studies, 45 (9), pp. 1496-1514.

Tipples, R. (2017). New Zealand agricultural employment relations, migration, and 'pledge washing'
- the new recipe for the 21st century, Lincoln, Nueva Zelanda: Faculty of Agribusiness \& Commerce Working Paper Series No. 19.

Underhill, E. y Rimmer, M. (2016). Layered vulnerability: Temporary migrants in Australian horticulture, Journal of Industrial Relations, 58 (5), pp. 608-626.

Underhill, E., Groutsis, D., Van den Broek, D., \& Rimmer, M. (2018). Migration Intermediaries and Codes of Conduct: Temporary Migrant Workers in Australian Horticulture. Journal of Business Ethics, 153(3), pp. 675-689.

United Nations (2018). World Economic Situation and Prospects 2018, Nueva York, Estados Unidos: United Nations.

Wallerstein, I. (1983). Historical Capitalism, Thetford, Reino Unido: Verso.

Wallerstein, I. (2000). The essential Wallerstein, Nueva York, Estados Unidos: The New Press.

Wallerstein, I. (2004) World-Systems Analysis. An Introduction, Durham, Reino Unido: Duke University Press. 


\section{ANEXo}

\section{FUENTES ESTADÍSTICAS CONSULTADAS}

\begin{tabular}{|c|c|c|c|c|}
\hline Fuente & Año & Tipo de Registro & Institución & País Emisor \\
\hline National Agricultural Workers Survey & 2015 & Encuesta & $\begin{array}{l}\text { U.S. Department of Labor } \\
\text { - Employment and Training } \\
\text { Administration }\end{array}$ & Estados Unidos \\
\hline $\begin{array}{l}\text { Nonimmigrant Visa Issuances by Visa Class and } \\
\text { by Nationality 1997-2017 }\end{array}$ & 2018 & Registro (Visados) & $\begin{array}{l}\text { US Department of State, } \\
\text { Bureau of Consular Affairs }\end{array}$ & Estados Unidos \\
\hline $\begin{array}{l}\text { Temporary Foreign Worker Program work permit } \\
\text { holders with valid permit(s) in calendar year by } \\
\text { program, } 2007 \text { to } 2016\end{array}$ & 2019 & $\begin{array}{l}\text { Registro (Permisos de } \\
\text { trabajo) }\end{array}$ & $\begin{array}{l}\text { Immigration, Refugees and } \\
\text { Citizenship Canada (IRCC) }\end{array}$ & Canadá \\
\hline $\begin{array}{l}\text { Derechos laborales de mexicanos en el } \\
\text { extranjero: Programa de Trabajadores Agrícolas } \\
\text { Temporales (PTAT). México-Canadá Temporadas } \\
2001 \text { - } 2018 \text { (octubre) }\end{array}$ & 2019 & $\begin{array}{l}\text { Registro (contrataciones } \\
\text { por acuerdo bilateral) }\end{array}$ & $\begin{array}{l}\text { Secretaría de Relaciones } \\
\text { Exteriores de México }\end{array}$ & México \\
\hline Census of Agriculture & 2016 & Registro (Censo) & Statistics Canada & Canadá \\
\hline $\begin{array}{l}\text { Working Holiday } \\
\text { Maker visa program } \\
\text { report }\end{array}$ & 2018 & Registro & $\begin{array}{l}\text { Australian Government } \\
\text { - Department of Home } \\
\text { Affairs }\end{array}$ & Australia \\
\hline SWP Visas & 2019 & Registro & $\begin{array}{l}\text { Development Policy Centre } \\
\text { (Devpolicy) }\end{array}$ & Australia \\
\hline $\begin{array}{l}\text { Statistics - Work Applications Approved by } \\
\text { Occupation }\end{array}$ & 2019 & $\begin{array}{l}\text { Registro (Permisos de } \\
\text { trabajo) }\end{array}$ & New Zealand Immigration & Nueva Zelanda \\
\hline Recognised Seasonal Employers (RSE) Arrivals & 2019 & $\begin{array}{l}\text { Registro (contrataciones } \\
\text { por acuerdo bilateral) }\end{array}$ & New Zealand Immigration & Nueva Zelanda \\
\hline JITCO Annual Reports & $2000-2018$ & Registro & $\begin{array}{l}\text { Japan International Training } \\
\text { Cooperation Organization } \\
\text { (JITCO) }\end{array}$ & Japón \\
\hline $\begin{array}{l}\text { Crop } \\
\text { production in national humidity [apro_cpnh1] }\end{array}$ & 2019 & $\begin{array}{l}\text { Registro (Estadísticas de } \\
\text { estructura productiva) }\end{array}$ & Eurostat & Unión Europea \\
\hline $\begin{array}{l}\text { First permits issued for remunerated activities by } \\
\text { reason, length of validity and citizenship } \\
\text { [migr_resocc] }\end{array}$ & 2019 & $\begin{array}{l}\text { Registro (Permisos de } \\
\text { residencia) }\end{array}$ & Eurostat & Unión Europea \\
\hline Encuesta de Población Activa & 2019 & Encuesta & INE & España \\
\hline Dataset: Occupati & 2019 & $\begin{array}{l}\text { Registro (Estadísticas } \\
\text { laborales) }\end{array}$ & ISTAT & Italia \\
\hline
\end{tabular}

